\title{
Coordinatively Unsaturated Ruthenium Complexes As Efficient Alkyne-Azide Cycloaddition Catalysts
}

\author{
Marina Lamberti, ${ }^{\dagger, \ddagger}$ George C. Fortman, ${ }^{\dagger}$ Albert Poater, $^{\S, \perp}$ Julie Broggi, $^{\dagger}$ Alexandra M. Z. Slawin, ${ }^{\dagger}$ \\ Luigi Cavallo," and Steven P. Nolan*, \\ ${ }^{\dagger}$ EaStCHEM School of Chemistry, University of St Andrews, St Andrews, KY16 9ST, U.K. \\ ${ }^{\ddagger}$ Dipartimento di Chimica e Biologia, Università di Salerno, Via Ponte don Melillo, I-84084 Fisciano (SA), Italy \\ ${ }^{\S}$ Catalan Institute for Water Research (ICRA), H2O Building, Scientific and Technological Park of the University of Girona, Emili \\ Grahit 101, E-17003 Girona, Spain \\ ${ }^{\perp}$ Institut de Química Computacional, Departament de Química, Universitat de Girona, Campus de Montilivi, E-17071 Girona, Spain \\ "KAUST Catalyst Research Center, 4700 King Abdullah University of Science and Technology, Thuwal 23955-6900, Kingdom of \\ Saudi Arabia
}

\section{Supporting Information}

ABSTRACT: The performance of 16-electron ruthenium complexes with the general formula $\mathrm{Cp} * \mathrm{Ru}(\mathrm{L}) \mathrm{X}$ (in which $\mathrm{L}=$ phosphine or $\mathrm{N}$-heterocyclic carbene ligand; $\mathrm{X}=\mathrm{Cl}$ or $\mathrm{OCH}_{2} \mathrm{CF}_{3}$ ) was explored in azide-alkyne cycloaddition reactions that afford the 1,2,3triazole products. The scope of the $\mathrm{Cp} * \mathrm{Ru}\left(\mathrm{P}^{i} \mathrm{Pr}_{3}\right) \mathrm{Cl}$ precatalyst was investigated for terminal alkynes leading to new 1,5-disubstituted 1,2,3-triazoles in high yields. Mechanistic studies were conducted and revealed a number of proposed intermediates. $\mathrm{Cp} * \mathrm{Ru}$ $\left(\mathrm{P}^{\mathrm{i}} \mathrm{Pr}_{3}\right)\left(\eta^{2}-\mathrm{HCCPh}\right) \mathrm{Cl}$ was observed and characterized by ${ }^{1} \mathrm{H},{ }^{13} \mathrm{C}$, and ${ }^{31} \mathrm{P} \mathrm{NMR}$ at temperatures between 273 and $213 \mathrm{~K}$. A rare example of $N, N-\kappa^{2}$-phosphazide complex, $\mathrm{Cp} * \mathrm{Ru}\left(\kappa^{2}-\mathrm{Pr}_{3} \mathrm{PN}_{3} \mathrm{Bn}\right) \mathrm{Cl}$, was fully characterized, and a single-crystal X-ray diffraction structure was obtained. DFT calculations describe a complete map of the catalytic reactivity with phenylacetylene and/or benzylazide.

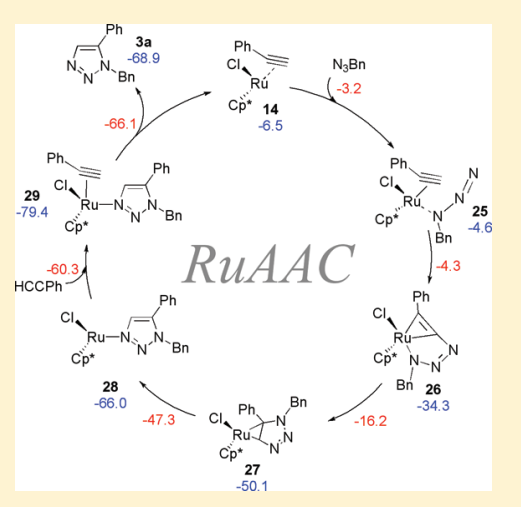

\section{INTRODUCTION}

While absent in natural products, the 1,2,3-triazoles are $\mathrm{N}$ heterocyclic compounds that constitute an important class of organic substrates owing to their diverse uses, ranging from industrial applications to a large number found in pharmaceutical compounds. ${ }^{1}$ The Huisgen 1,3-dipolar cycloaddition of alkynes (1) and azides (2) was the first reported direct route to produce these interesting products. ${ }^{2}$ This thermal process, known for more than a century, has a limited scope due to its low regioselectivity and the required high reaction temperatures. ${ }^{3}$ More recently, catalytic processes to obtain exclusively 1,4- or 1,5-disubstitued regioisomers have been reported in the literature, and a schematic representation of this transformation is depicted in eq 1 .

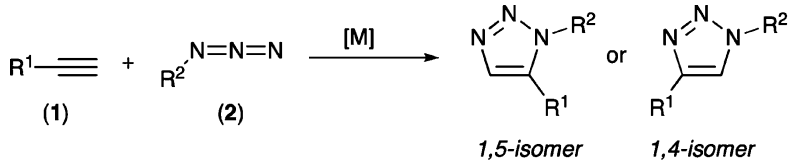

(3)
In particular, Meldal ${ }^{4}$ and Sharpless ${ }^{5}$ independently reported in 2002 the $\mathrm{Cu}(\mathrm{I})$-catalyzed azide-alkyne cycloaddition (CuAAC), which regioselectively leads to the 1,4-disubstituted 1,2,3-triazoles. Later, Fokin in collaboration with Jia ${ }^{6}$ reported the $\mathrm{Ru}(\mathrm{II})$-catalyzed approach (RuAAC) toward complementary regioisomers, the 1,5-disubstituted 1,2,3-triazoles.

The CuAAC reaction, considered as one of the most powerful click reactions, ${ }^{7}$ has been the focus of significant research activity. Much effort has been devoted to unravel its mechanism, ${ }^{8}$ whereas only a few papers have appeared in the literature regarding the RuAAC reaction. ${ }^{6,9}$

According to the proposed mechanism for RuAAC, ${ }^{6}$ the catalytically active species is the neutral " $\mathrm{Cp} * \mathrm{RuCl}$ " species, produced by the displacement of spectator ligands from the 18electron ruthenium complexes, which then undergoes an oxidative coupling of the azide and the alkyne to give a sixmembered ruthenacycle intermediate. Subsequent reductive elimination releases the aromatic triazole product.

The extrusion of ligands to create coordinative unsaturation at the metal center is obviously of central relevance. Within this context, we proposed to investigate whether coordinatively unsaturated 16-electron complexes $\mathrm{Cp} * \mathrm{Ru}(\mathrm{L}) \mathrm{Cl}$ might exhibit improved performance in this catalytic process and extend this study to include other representative ligands, such as $\mathrm{N}$ heterocyclic carbenes (NHCs). ${ }^{10}$

Received: December 14, 2011

Published: January 10, 2012 
Stable coordinatively unsaturated ruthenium complexes $\mathrm{Cp} * \mathrm{Ru}(\mathrm{L}) \mathrm{X}$, in which $\mathrm{L}$ represents a sterically demanding phosphine or an NHC ligand and X represents a halide or an alkoxide ligand, are well-known in the literature. ${ }^{11}$ Moreover, the binding of these imidazole- and phosphine-based ligands to the $\mathrm{Cp} * \mathrm{RuCl}$ moiety was thoroughly investigated by thermochemistry and structural studies. ${ }^{12}$ A linear correlation between the experimental bond dissociation energies (BDEs) of this class of complexes and the $\% V_{\mathrm{Bur}}{ }^{13}$ (the percent of a volume occupied by ligand atoms in a sphere centered about a metal) of the corresponding ligands was found, ${ }^{14}$ suggesting that the BDEs are significantly affected by the steric requirements of the ligand.

In the present contribution, the activity of $\mathrm{Cp} * \mathrm{Ru}(\mathrm{L}) \mathrm{X}$ complexes $\mathbf{6 a}-\mathbf{f}$ and $7 \mathbf{a}$ in which $\mathrm{L}$ is a NHC (Figure 1) ligand

IAd: $\mathrm{R}=$ adamantyl
IPr: $\mathrm{R}=2,6$-diisopropylphenyl
ICy: $\mathrm{R}=$ cyclohexyl
IMes: $\mathrm{R}=$ mesityl

Figure 1. NHC ligands used in this work.

or phosphine ligand and $\mathrm{X}$ is a chloride or an alkoxide group (eqs 2 and 3 ) has been investigated as catalysts in the

$$
\begin{aligned}
& {\left[\mathrm{Cp}^{*} \mathrm{RuCl}\right]_{4}+4 \mathrm{~L} \longrightarrow 4 \mathrm{Cp}{ }^{*} \mathrm{Ru}(\mathrm{L}) \mathrm{Cl} \quad \mathrm{L}=\mathrm{PiPr}_{3}(\mathrm{a})} \\
& \text { (4) (5a-f) (6a-f) } \quad=\operatorname{lAd}(\mathbf{c}) \\
& =\operatorname{IPr}(\mathrm{d}) \\
& =\operatorname{ICy}(\mathrm{e}) \\
& =\text { IMes (f) } \\
& \mathrm{Cp}{ }^{*} \mathrm{Ru}\left(\mathrm{PiPr}_{3}\right) \mathrm{Cl}+\mathrm{Tl}\left(\mathrm{OCH}_{2} \mathrm{CF}_{3}\right) \longrightarrow \mathrm{Cp}{ }^{*} \mathrm{Ru}\left(\mathrm{P}^{\mathrm{i} \mathrm{Pr}_{3}}\right)\left(\mathrm{OCH}_{2} \mathrm{CF}_{3}\right) \\
& \text { (7a) }
\end{aligned}
$$

cycloaddition reaction of benzylazide with phenylacetylene to afford the 1,2,3-triazole compound. The scope of the reaction catalyzed by the $\mathrm{Cp} * \mathrm{Ru}\left(\mathrm{P}^{i} \mathrm{Pr}_{3}\right) \mathrm{Cl}$ complex, which showed the best activity among the examined catalysts, was explored for both terminal and internal alkynes. Mechanistic studies, performed by means of NMR experiments and DFT calculations, allowed the description of both the catalyst activation and the productive catalytic cycle.

\section{RESULTS AND DISCUSSION}

Catalytic Activity. Following literature procedures, ${ }^{11 a, b, 15}$ the chloro complexes $\mathbf{6 a}-\mathbf{f}$ were obtained by mixing a solution of the ligand $\mathrm{L}$ (5a-f, 4 equiv) in THF and the tetramer $[\mathrm{Cp} * \mathrm{RuCl}]_{4}$ (4) (1 equiv) at room temperature (eq 2), whereas the alkoxo complex $7 \mathbf{a}$ was synthesized by reacting the corresponding chloro complex $6 \mathbf{a}$ with $\mathrm{Tl}\left(\mathrm{OCH}_{2} \mathrm{CF}_{3}\right)$ (eq 3). ${ }^{16}$

Complexes 6 and 7 were employed as precatalysts for the cycloaddition reaction of benzylazide and phenylacetylene as model substrates. The results of this study are presented in Table 1. For comparison, the analogous reaction catalyzed by the $[\mathrm{Cp} * \mathrm{RuCl}]_{4}(4)$ precursor is also reported. The reactions were carried out in dichloromethane (DCM) at room temperature with $1 \mathrm{~mol} \%$ ruthenium catalyst. In all cases, the 1,5-regioisomer was the only product. The metal-free reactions (control reaction) conducted under the same conditions gave $<1 \%$ conversion (Table 1 , entries 9 and 10).

Complexes $\mathbf{6 a}$ and $\mathbf{6 b}$ exhibited the best catalytic performance (Table 1, entries 1 and 2). Among the NHC-based complexes, the highest conversion was obtained with complex 6c, which bears the IAd ligand, which is the most sterically demanding among the explored NHC ligands (Table 1, entry 3 ). Nevertheless, the obtained conversions and the $\% V_{\text {bur }}$ of the examined L ligands did not show a linear correlation. Therefore, the catalytic behavior of these ruthenium complexes cannot simply be correlated with the steric requirements of $\mathrm{L}$ ligands.

The effect of the anionic ligand was also investigated. In particular, in the aforementioned conditions, the alkoxo complex, 7a, produced only traces of the expected 1,2,3triazole (Table 1, entry 7 ), which suggests that the chloride has an important role in this catalytic process. Although the $[\mathrm{Cp} * \mathrm{RuCl}]_{4}$ precursor showed good conversion, the activities of the 16-electron phosphine-based ruthenium complexes (6a and $\mathbf{6 b}$ ) proved higher.

\begin{tabular}{|c|c|c|c|}
\hline entry & {$[\mathrm{Ru}]$} & & $\operatorname{conv}^{b}[\%]$ \\
\hline 1 & $\mathrm{Cp} * \mathrm{Ru}\left(\mathrm{P}^{i} \mathrm{Pr}_{3}\right) \mathrm{Cl}$ & $6 a$ & 89 \\
\hline 2 & $\mathrm{Cp} * \mathrm{Ru}\left(\mathrm{PCy}_{3}\right) \mathrm{Cl}$ & $6 b$ & 87 \\
\hline 3 & $\mathrm{Cp} * \mathrm{Ru}(\mathrm{IAd}) \mathrm{Cl}$ & $6 c$ & 67 \\
\hline 4 & $\mathrm{Cp}^{*} \mathrm{Ru}(\mathrm{IPr}) \mathrm{Cl}$ & $6 d$ & 58 \\
\hline 5 & $\mathrm{Cp} * \mathrm{Ru}(\mathrm{ICy}) \mathrm{Cl}$ & $6 e$ & 8 \\
\hline 6 & $\mathrm{Cp} * \mathrm{Ru}(\mathrm{IMes}) \mathrm{Cl}$ & $6 f$ & 4 \\
\hline 7 & $\mathrm{Cp}^{*} \mathrm{Ru}\left(\mathrm{P}^{i} \mathrm{Pr}_{3}\right)(\mathrm{OR})^{c}$ & $7 a$ & 2 \\
\hline 8 & {$[\mathrm{Cp} * \mathrm{RuCl}]_{4}$} & 4 & 68 \\
\hline 9 & & & $<1$ \\
\hline 10 & $\mathrm{P}^{i} \mathrm{Pr}_{3}$ & $5 a$ & $<1$ \\
\hline
\end{tabular}

The influence of the order of the addition of the substrates on the catalytic activity was explored. For complex 6a, we found that the addition of the alkyne prior to addition of the azide caused a lowering of the conversion (6-fold), whereas adding the azide before the alkyne did not show a significant difference with respect to the addition of a mixture of the substrates to the

Table 1. Catalytic Activity of 16-Electron Ruthenium Precatalysts in the Cycloaddition Reaction of Benzylazide and Phenylacetylene ${ }^{a}$

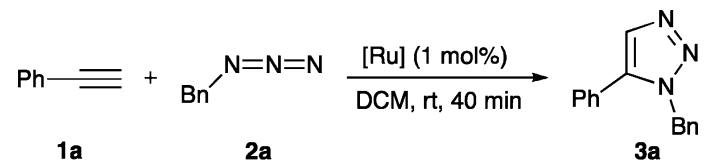


solution of the catalyst. This behavior can be explained in light of the observed reactivity of the catalyst with each substrate (vide infra).

Table 2 shows the results of a solvent screening on the model reaction catalyzed by $\mathbf{6} \mathbf{a}$. The highest cycloaddition reaction

Table 2. Effect of Solvents on the Conversion (\%) of the Model Reaction ${ }^{a}$

$\begin{array}{ccccccccc}\text { neat } & \text { water } & { }^{i} \mathrm{PrOH} & \text { pentane } & \text { toluene } & \text { THF } & \text { DMF } & \text { dioxane } & \text { DCM } \\ 9 & 9 & 16 & 22 & 49 & 65 & 70 & 75 & 89\end{array}$

${ }^{a}$ Reaction conditions: catalyst 6a, $1 \mathrm{~mol} \%$; solvent, $2 \mathrm{~mL}$; time, 40 $\mathrm{min}$; room temperature; azide/alkyne $=1: 1.05$. Conversion determined by GC, average of two runs.

efficiency was observed in coordinating solvents, such as tetrahydrofuran, dimethylformamide, dioxane, and dichloromethane. Lower conversions were obtained in nonpolar hydrocarbon solvents, such as pentane and toluene. Polar protic solvents, including water and 2-propanol, led to very low conversions as well. Presumably, a good balance of polarity and coordinating ability makes dichloromethane the best performing solvent for this reaction.

Concentrations and catalyst loadings were examined, showing that the highest efficiency is obtained at $1 \mathrm{~mol} \%$ and $2.5 \mathrm{mM}$ of catalyst (Table 3 ). As discussed in the following

Table 3. Variation of Concentration and Loading of Catalyst $^{a}$

$\begin{array}{ccc}\text { solvent }(\mathrm{mL}) & {[\mathrm{Ru}](\mathrm{mol} \%)} & \text { conv }(\%)^{b} \\ 0.1 & 1.0 & 9 \\ 1 & 1.0 & 18 \\ 2 & 1.0 & 66 \\ 2 & 1.0 & 89 \\ 2 & 1.0 & 98^{c} \\ 2 & 0.5 & 52 \\ & 0.1 & 6\end{array}$

${ }^{a}$ Reaction conditions: catalyst $6 \mathrm{a}$; solvent, DCM; time, $40 \mathrm{~min}$; room temperature; azide/alkyne $=1: 1.05$. ${ }^{b}$ Conversion determined by GC, average of two runs. ${ }^{c}$ Reaction at $40{ }^{\circ} \mathrm{C}, 30 \mathrm{~min}$.

mechanistic section, concentrations of the catalyst and substrates play a significant role in defining the catalytic efficiency. Finally, the reaction performed at $40^{\circ} \mathrm{C}$ was found to be faster than the one at room temperature, leading to reaction completion within $30 \mathrm{~min}$ (98\% conversion).

With the optimized conditions in hand, we extended the scope of the RuAAC reaction to include different alkynes and azides. Scheme 1 outlines the obtained 1,5-disubstituted 1,2,3triazoles with the corresponding reaction times and isolated yields after flash chromatography. Whereas benzyl and alkyl azides reached full conversions in short reaction times, the cycloaddition of phenyl azides yielded a mixture of products, in line with previous findings. ${ }^{6 a}$ Aryl and alkyl alkynes were found to be suitable cycloaddition partners, as well as enynes. For aryl alkynes, a significant effect of the substituents on the phenyl ring was found (cf. $\mathbf{3 f}$ vs $\mathbf{3 g}$ ). In particular, a better catalytic performance was obtained with the alkyne bearing an electrondonating substituent. Propargylic alcohols (triazoles $\mathbf{3 h}-\mathbf{3} \mathbf{j}$ ) were found to be extremely active at room temperature, as apparent from the reaction solution turning orange in color and boiling as these alkynes were added. The scope of the RuAAC
Scheme 1. Formation of 1,5-Disubstituted 1,2,3-Triazoles Catalyzed by Complex $1^{a}$
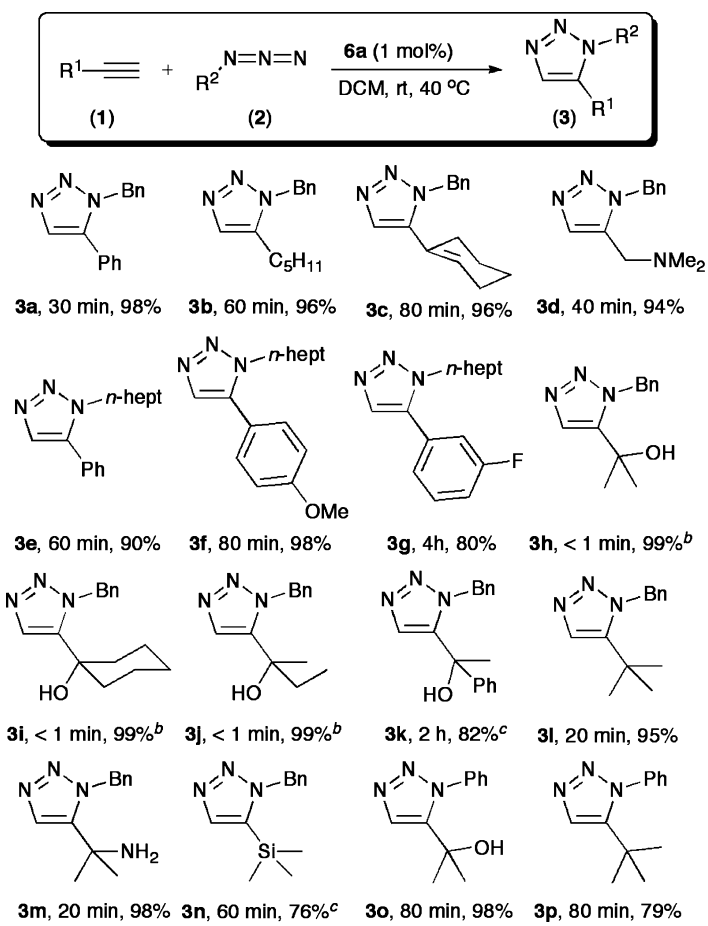

${ }^{a}$ Reaction times and isolated yields after flash chromatography are reported for each triazole product. Reaction conditions: Catalyst 6a, 1 $\mathrm{mol} \%$; DCM, $2 \mathrm{~mL}$; azide/alkyne $=1: 1.05,40{ }^{\circ} \mathrm{C}$. ${ }^{b}$ Room temperature. ${ }^{c} 2$ mol \% catalyst 6 .

with 1,1-disubstituted propargylic alcohols and amines was previously investigated with 18 -electron ruthenium complexes as precatalysts. ${ }^{6 c}$ By comparison, the 16-electron complex $6 a$ gave more rapid conversions operating under milder conditions.

Because of the excellent activity observed with $1,1^{\prime}$ disubstituted propargylic alcohols, we decided to investigate the effect of the substituents on the $\alpha$ carbon and of the position of the hydroxyl group relative to the triple bond. Surprisingly, we observed that the cycloaddition reactions with benzylazide and the alkynes, described in Figure 2, did not

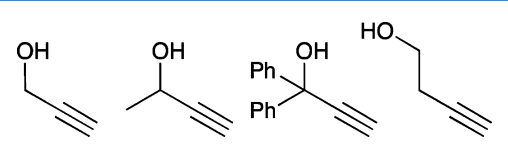

Figure 2. Unreactive alkynes in the cycloaddition reaction with benzylazide, catalyzed by $\mathbf{6 a}$.

proceed at all under the optimized conditions. Conversely, increasing the catalyst loading and the reaction time led to the conversion of 2-phenyl-3-butyn-2-ol to the corresponding triazole in good yield (3k). These results suggest that propargylic alcohols need a suitable substitution pattern to be highly reactive in the cycloaddition reaction. Next, we turned our attention to tertiary alkynes in which the hydroxyl group of 2-methyl-3-butyn-2-ol is replaced with different moieties. Interestingly, 1,5-triazole products were obtained in excellent yields and in very short reaction times in the case of 3,3dimethyl-1-butyne and 2-methyl-3-butyn-2-amine ( 31 and $3 \mathrm{~m}$ ), suggesting that electron-donating groups on the carbon at the $\alpha$ 
position to the triple bond of the alkyne substrate promote higher reactivity. The chemical nature of the atom in this position also plays a crucial role in the activity, as the trimethylsilylacetylene needed a longer reaction time and higher catalyst loading to reach good conversion (3n).

The most reactive alkynes were also found able to react with phenylazide to afford efficiently the corresponding 5-aryl 1,2,3triazoles (3o and 3p). Although a number of 1,5-disubstituted triazoles from aryl azides and alkynes were previously synthesized with ruthenium-based catalysts, ${ }^{6}$ complex $\mathbf{6 a}$ led to complete conversions under milder conditions and very short reaction times.

Next, we turned to the cycloaddition of internal alkynes. As known in the literature, the CuAAC is limited to terminal alkynes, while $\mathrm{Ru}$ catalysis has been extended to the more challenging cycloaddition of internal alkynes. ${ }^{6,9,17}$ Table 4

Table 4. Formation of 1,4,5-Trisubstituted 1,2,3-Triazoles Catalyzed by Complex $6 a^{a}$

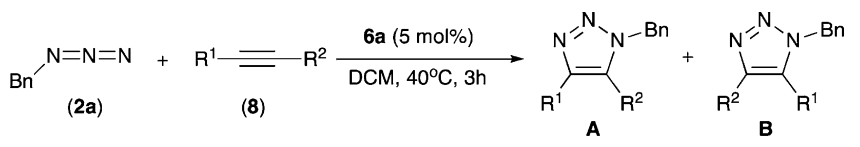

(9)

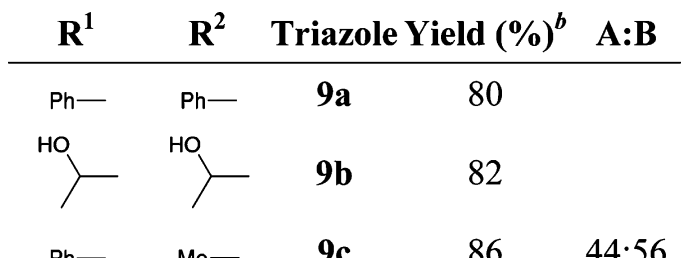

${ }^{a}$ Reaction conditions: catalyst $6 \mathrm{a}, 5 \mathrm{~mol} \%$; DCM, $2 \mathrm{~mL}$; azide/alkyne $=1: 1.05 ; 3 \mathrm{~h} ; 40{ }^{\circ} \mathrm{C} .{ }^{b}$ Isolated yields after flash chromatography.

displays the results of our investigation with RuAAC and the more challenging alkyne substrates. When diphenylacetylene and benzylazide were added to a solution of catalyst $\mathbf{6 a}$ in dichloromethane, the triazole 9a was obtained in good yield after $3 \mathrm{~h}$. The uncatalyzed reaction executed under the same conditions did not proceed at all.

As observed for terminal alkynes, the activity of the internal alkynes bearing hydroxyl groups on the carbon atoms in position $\alpha$ to the triple bond strongly depends on the $\mathrm{C}_{\alpha}$ substituents. In this case, the secondary alcohol showed a good reactivity (Table $4,9 \mathbf{b}$ ), and the primary and the tertiary ones were found unreactive in the reaction with benzylazide.

An unsymmetrical alkyne was also tested (Table 4, 9c). The regioisomer ratio and the regiochemistry of the products were evaluated by comparison of ${ }^{1} \mathrm{H}$ NMR with literature data. In line with what we observed in the case of terminal alkynes, complex 6a showed better catalytic performance with respect to the 18-electron ruthenium complexes. ${ }^{9}$ On the other hand, no significant differences were observed for the regiospecificity of these different catalysts.

Mechanistic Studies. To gain mechanistic insights into the RuAAC catalytic process, a number of variable-temperature NMR experiments were performed. During the stoichiometric reaction leading to the formation of the triazole $3 \mathbf{a}$, no intermediates were observed when reacting $\mathrm{Cp} * \mathrm{Ru}\left(\mathrm{P}^{i} \mathrm{Pr}_{3}\right) \mathrm{Cl}$ (6a) with 1 equiv of both phenylacetylene (1a) and benzylazide (2a) at $223 \mathrm{~K}$. To decrease the reaction rate, with the aim of observing intermediate species, an NMR reaction was conducted under catalytic conditions but using $5 \mathrm{~mol} \%$ catalyst. A selected region of NMR spectra collected during this experiment is shown in Figure 3. ${ }^{18}$

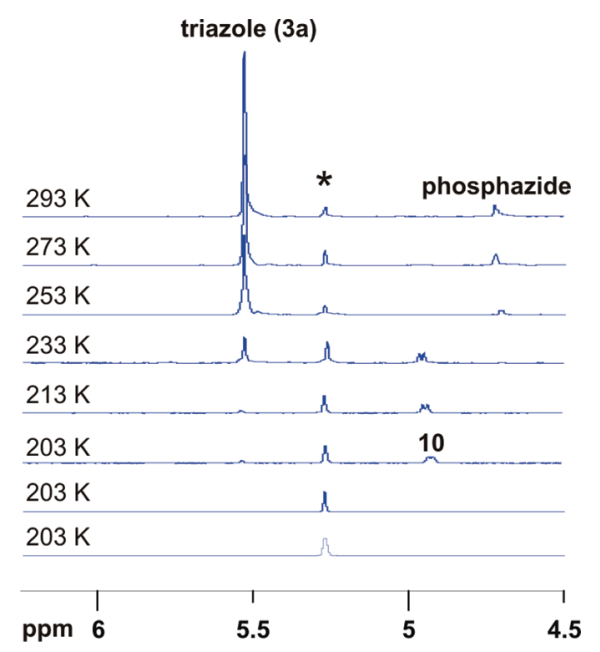

Figure 3. Selected region of VT ${ }^{1} \mathrm{H}$ NMR spectra of the reaction mixture of complex $\mathbf{6 a}$, benzylazide $\mathbf{2 a}$ (20 equiv), and phenylacetylene 1a (20 equiv) in $\mathrm{CD}_{2} \mathrm{Cl}_{2}$.

The bottom spectrum in Figure 3, recorded at $203 \mathrm{~K}$, contains only complex 6a. The next two spectra are after the addition of 20 equiv of the two substrates. Within 5 min after substrate addition at $203 \mathrm{~K}$, shifts assigned to the triazole $(\delta=$ $5.6 \mathrm{ppm})$ and an intermediate species $(\delta=5.0 \mathrm{ppm})$ appear. This intermediate is assigned as an $\eta^{2}$-alkyne Ru complex (10) (see below). The intensity of the chemical shifts assigned to the intermediate and triazole continue to grow as the temperature is increased from 213 to $233 \mathrm{~K}$. Between 233 and $253 \mathrm{~K}$, intermediate 10 disappears. In the same range of temperatures, ${ }^{1} \mathrm{H}$ and ${ }^{31} \mathrm{P}$ NMR revealed the appearance of shifts denoting the formation of free phosphine and of the phosphazide ${ }^{i} \operatorname{Pr}_{3} \mathrm{P}=$ $\mathrm{N}_{3} \mathrm{Bn}(\delta=4.7 \mathrm{ppm}) .^{18} \mathrm{By}$ the end of the reaction at $293 \mathrm{~K}$, both substrates were consumed. Unfortunately, the ultimate fate of the $\mathrm{Ru}$ catalyst was unknown, as no assignable shifts were observed. The presence of the phosphazide was constant throughout substrate consumption. The formation of the phosphazide is in line with the assumption that the neutral $\mathrm{Cp} * \mathrm{RuCl}$ is the catalytically active species. ${ }^{6 c}$

The initial exploration of the reaction profile under variable temperatures prompted further studies with each substrate. In doing this we had hoped to gain more information about the initiation of the precatalyst, formation of transient intermediates, and the nature of the active catalytic species.

Reaction of $\left[\mathrm{Cp} * \mathrm{Ru}\left(\mathrm{P}^{i} \mathrm{Pr}_{3}\right) \mathrm{Cl}\right](6 \mathrm{a})$ with Phenyacetylene (1a). The reaction of $6 \mathrm{a}$ with 1 equiv of $\mathrm{HC} \equiv \mathrm{CPh}$, carried out at $203 \mathrm{~K}$ in $\mathrm{CD}_{2} \mathrm{Cl}_{2}$, led to the formation of $\eta^{2}$-alkyne $\mathrm{Ru}$ complex 10, as shown in eq 4 . This species was characterized at

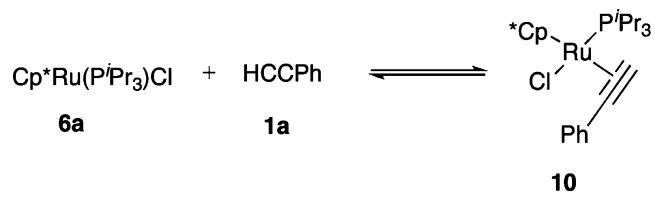

the same temperature by ${ }^{1} \mathrm{H},{ }^{13} \mathrm{C}$, and ${ }^{31} \mathrm{P}$ NMR spectroscopy. ${ }^{19}$ In the ${ }^{1} \mathrm{H}$ NMR spectrum, the signal of the $\mathrm{Cp} *$ methyl groups and of the coordinated phosphine did not show significant 
change with respect to those observed for 6a. Most tellingly, a doublet appeared at $4.96 \mathrm{ppm}\left({ }^{3} J_{\mathrm{PH}}=7.7 \mathrm{~Hz}\right)$ for the acetylenic proton of the phenylacetylene. The splitting of this signal was reduced to a singlet when executing ${ }^{1} \mathrm{H}\left\{{ }^{31} \mathrm{P}\right\}$ NMR experiments, confirming the presence of proton-phosphorus coupling. In the ${ }^{31} \mathrm{P}\left\{{ }^{1} \mathrm{H}\right\}$ NMR spectrum only one resonance was present at $38.54 \mathrm{ppm}$. Finally, in the ${ }^{13} \mathrm{C}$ NMR spectrum, the aliphatic carbons of the phenylacetylene were found at $72.62 \mathrm{ppm}\left(\mathrm{C} \equiv \mathrm{CH},{ }^{2} J_{\mathrm{PC}}=2.0 \mathrm{~Hz}\right)$ and $87.48 \mathrm{ppm}(\mathrm{C} \equiv$ $\mathrm{CH})$, and the quaternary nature of this carbon was confirmed by DEPT experiments. All spectroscopic data of the new ruthenium species were consistent with the formation of the $\eta^{2}$-phenylacetylene complex 10, shown in eq 4 .

The evolution of complex 10 was followed by variabletemperature ${ }^{1} \mathrm{H}$ and ${ }^{31} \mathrm{P}$ NMR experiments. ${ }^{20}$ A selected range of ${ }^{1} \mathrm{H}$ NMR spectra are shown in Figure 4, in the range 213 to

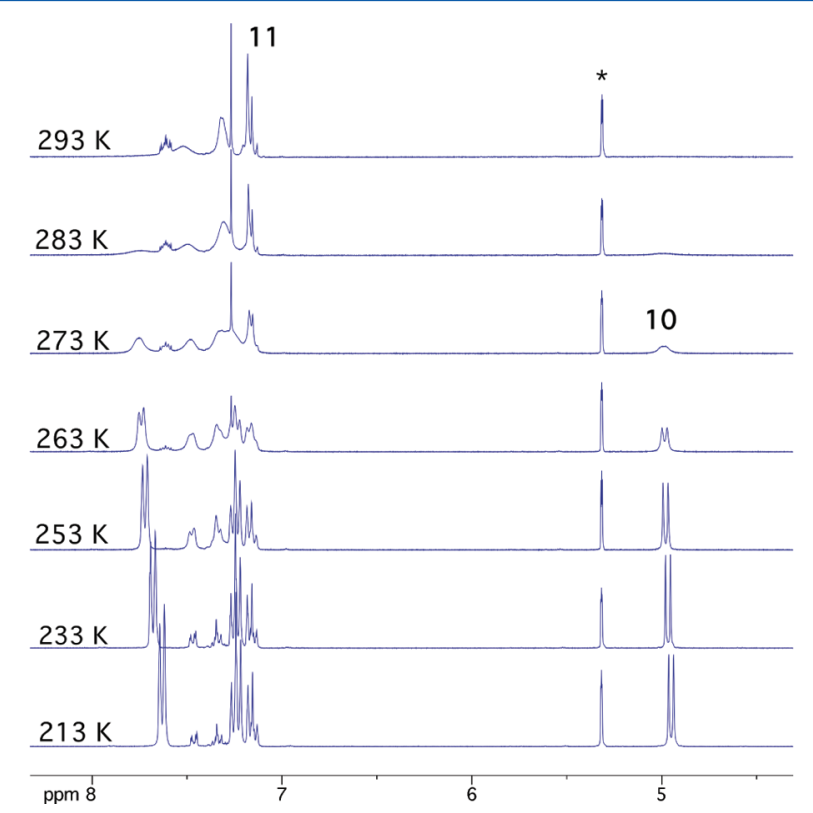

Figure 4. Selected region of variable-temperature ${ }^{1} \mathrm{H}$ NMR spectra of the reaction mixture of complex 6 a and phenylacetylene (1 equiv) in $\mathrm{CD}_{2} \mathrm{Cl}_{2}$ (the signal denoted with $*$ indicates protio impurities). The temperature for each spectrum is shown on the left. The first spectrum shows only the $\eta^{2}$-phenylacetylene complex 10 . The sequence for the conversion of 10 to species 11 can be seen as the temperature increases.

$293 \mathrm{~K}$. Upon warming, species 10 evolved to complex 6 a by releasing phenylacetylene, and the conversion was complete at $273 \mathrm{~K}$. Concurrently, at temperatures greater than $263 \mathrm{~K},{ }^{31} \mathrm{P}$ spectra revealed the formation of free phosphine. This coincided with the evolution of the reaction monitored by ${ }^{1} \mathrm{H}$ NMR spectroscopy, which showed the formation of the new species 11 (see eq 5). According to the ${ }^{1} \mathrm{H}$ NMR spectrum,

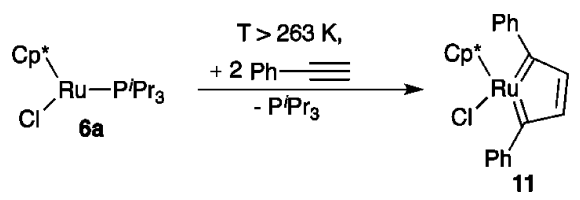

(5)

species 11 coordinates 2 equiv of phenylacetylene, while releasing 1 equiv of free phosphine.
At $293 \mathrm{~K}$, the reaction mixture consisted of $\mathbf{6 a}$, species $\mathbf{1 1}$, and free $P^{i} \operatorname{Pr}_{3}$. Subsequently, complex 11 was synthesized at room temperature by mixing complex $\mathbf{6 a}$ with an excess of phenylacetylene, and its structure was assigned on the basis of ${ }^{1} \mathrm{H}$ and ${ }^{13} \mathrm{C}$ NMR spectroscopy.

As well-known in the literature, the $\mathrm{CpRuCl}$ fragment is an active species in the cyclotrimerization of alkynes. ${ }^{21}$ On the basis of DFT calculations, the first intermediate of this class of reaction was proposed to be the metallacyclopentatriene generated through oxidative coupling of two alkyne ligands. Confirming this hypothesis, some stable metallacycles were characterized by NMR spectroscopy and/or X-ray diffraction study. ${ }^{22,23}$ Specifically, the crystal structure of a cationic species similar to complex $11^{23}$ induced us to hypothesize that the phenyl substituents are in the $\alpha$ position of the metallacycle. Moreover, the stability of the different substitution patterns was evaluated by computational calculations (vide infra).

The ${ }^{1} \mathrm{H}$ NMR spectrum of the species 11 showed one signal for the methyl groups of the $\mathrm{Cp}^{*}$ and three resonances in the aromatic region. A singlet at $7.27 \mathrm{ppm}$, accounting for two protons, indicated the formation of a symmetrical metallacycle in which the hydrogen atoms are magnetically equivalent. Moreover, the appearance of ${ }^{13} \mathrm{C}$ resonances at 262.6 and 155.2 ppm, assignable to $\mathrm{C}_{\alpha}$ and $\mathrm{C}_{\beta}$ of the metallacycle, are the most indicative signals of the formation of the metallacyclopentatriene. The ${ }^{13} \mathrm{C}$ NMR data are consistent with those reported by Jia et al., who proposed the production of complex 11 through the reaction of $\mathrm{Cp}^{*} \mathrm{RuCl}(\mathrm{COD})$ in the presence of 5 equiv of phenylacetylene. ${ }^{23}$

The addition of 20 equiv of benzylazide to a solution containing metallacycle 11 (prepared by mixing complex 6a with 20 equiv of phenylacetylene) gave only $3 \%$ conversion to the triazole $3 \mathbf{a}$ at room temperature, strongly suggesting that complex 11 is not an effective intermediate in the catalytic cycle of the RuAAC. Accordingly, the ruthenacyclopentatriene, obtained by reaction of $\left[\mathrm{Cp}^{*} \mathrm{RuCl}\right]_{4}$ and 1,6-diyne, was reported to be unreactive with phenylethylazide. ${ }^{6 c}$

The previous experiments allowed for the demonstration of the proposed mechanism shown in Scheme 2. Complex 6a reacts with phenylacetylene at $203 \mathrm{~K}$, and the alkyne-metal $\pi$

Scheme 2. Proposed Reactivity of Complex 6a with Phenylacetylene at Various Temperatures and the Subsequent Reactivity with Benzylazide

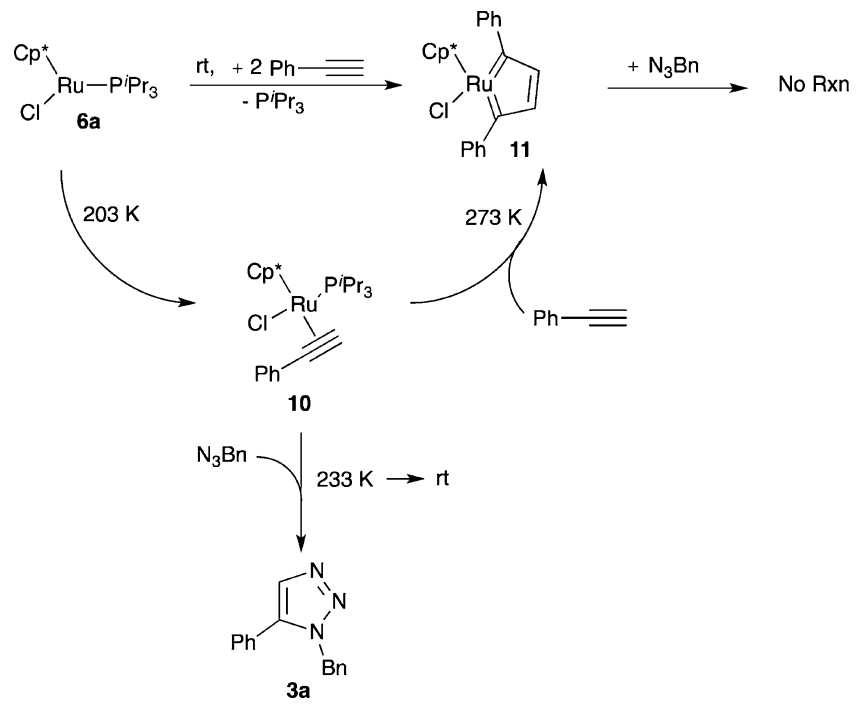


complex $\mathbf{1 0}$ is exclusively formed, but at temperatures closer to $273 \mathrm{~K}$ it is converted into complex 11. On the other hand, upon warming the solution of $\mathbf{1 0}$ in the presence of benzylazide, the formation of the triazole $3 a$ is favored with respect to the formation of complex 11.

In light of these experimental results, the detrimental lowering of the conversion observed for the cycloaddition reaction when the alkyne is first added to a solution of complex 6a can be explained keeping in mind that the metallacycle 11, which is favored at room temperature in the absence of the azide, is not catalytically active in the cycloaddition reaction.

Reaction of $\left[\mathrm{Cp} * \mathrm{Ru}\left(\mathrm{P}^{i} \mathrm{Pr}_{3}\right) \mathrm{Cl}\right]$ (6a) with Benzylazide (2a). The reaction of $6 \mathrm{a}$ with 1 equiv of benzylazide, carried out at room temperature in dichloromethane- $d_{2}$, led to the formation of two new species, 12 and 13, as shown in eq 6 . Additionally, free phosphine and unreacted complex 6a were observed in the reaction mixture.

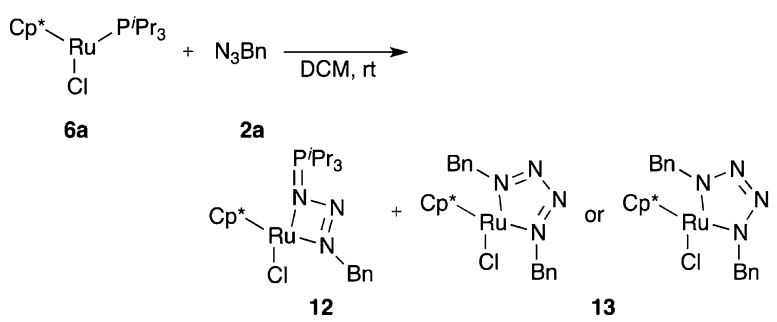

In the Staudinger reaction, ${ }^{24}$ involving a tertiary phosphine and an organic azide, the initial product is a phosphazide, which predominantly produces a phosphimine with expulsion of dinitrogen. In a similar manner, organic azides can react with complexes having phosphines as ligands, leading to phosphazide complexes. ${ }^{25,26}$ Another reported reaction between organic azides and phosphine complexes involves the formation of tetraazametallacyclopentene complexes, which usually takes place via transient metal imido intermediates. ${ }^{26,27}$

The ${ }^{1} \mathrm{H}$ NMR spectrum of species 12 showed an $\mathrm{AB}$ pattern $\left(J_{\mathrm{HH}}=11.44 \mathrm{~Hz}\right)$ for the $\mathrm{CH}_{2}$ protons of benzylazide. The signals for the coordinated phosphine shifted toward lower field with respect to the same signal in complex $\mathbf{6 a}$, while the signal of the $\mathrm{CH}_{3}$ of $\mathrm{Cp}^{*}$ shifted toward higher field. Signal intensities indicated that species 12 contains 1 equiv of benzylazide. In the ${ }^{31} \mathrm{P}$ NMR spectrum a signal at $58.12 \mathrm{ppm}$ appeared. In preparative scale reactions, complex 12 could be isolated by precipitation of the crude product from a mixture of toluene and hexane.

Gratifyingly, we were also able to obtain single crystals suitable for X-ray diffraction studies. ${ }^{28}$ Figure 5 shows an ORTEP representation of complex 12. To the authors' knowledge, this is a unique example of a $\mathrm{Ru}(\mathrm{II})-\left(\kappa^{2}-\right.$ phosphazide) complex. Danopoulos and Hursthouse reported an octahedral $\mathrm{Ru}(\mathrm{III})-\left(\kappa^{2}\right.$-phosphazide $)$ complex. $^{26}$ In totality, there are only a handful of transition metal bound phosphazide complexes reported to date. ${ }^{25}$

$\mathrm{Cp} * \mathrm{Ru}\left(\kappa^{2}{ }_{-}^{i} \mathrm{Pr}_{3} \mathrm{PN}_{3} \mathrm{Bn}\right) \mathrm{Cl}$ is formally a $\mathrm{d}^{6}$, 18 -electron complex. It is best viewed as a classical three-leg piano stool type complex. The N1-Ru1-N3 bite angle is 57.11(7) ${ }^{\circ}$. The phosphazide is somewhat tilted in its coordination. The Rul$\mathrm{N} 1$ bond length is $2.281 \AA$, while the Ru1-N2 bond length is $2.108 \AA$. These bond lengths and angles are similar to those found in the $\mathrm{Ru}(\mathrm{III})$ complex described by Danopoulos and Hursthouse. $^{26}$

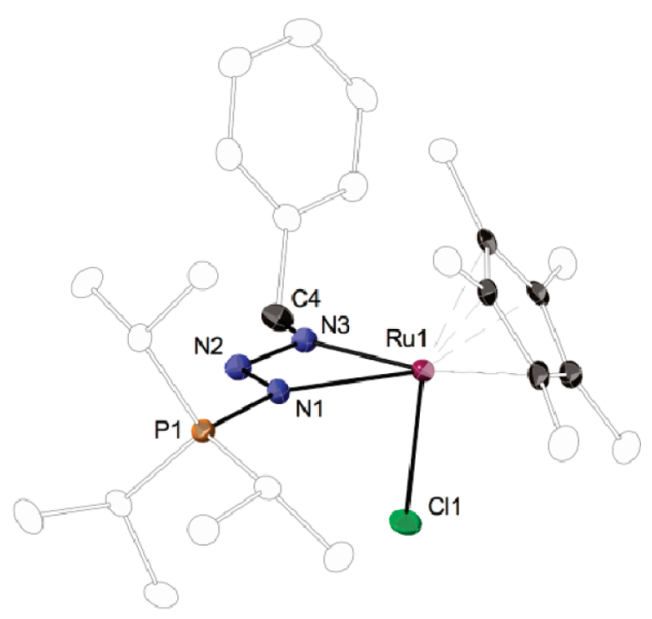

Figure 5. ORTEP representation of the bound phosphazide complex $\mathrm{Cp} * \mathrm{Ru}\left(\kappa^{2}-{ }^{i} \mathrm{Pr}_{3} \mathrm{PN}_{3} \mathrm{Bn}\right) \mathrm{Cl}(12)$. Selected bond lengths and angles: Ru1-N1 2.281(2) Å, Ru1-N3 2.108(2) Å, P1-N1 1.648(2) Å, N1Ru1-N3 57.11 ${ }^{\circ}$.

The minor product, species 13 , also showed an $\mathrm{AB}$ pattern $\left(J_{\mathrm{HH}}=14.32 \mathrm{~Hz}\right)$ for the $\mathrm{CH}_{2}$ protons of benzylazide, the signal of the $\mathrm{CH}_{3}$ of $\mathrm{Cp}^{*}$ shifted toward lower field, and the concomitant formation of 1 equiv of free phosphine was observed. According to the signal intensity ratio, species 13 contains 2 equiv of azide. Confirmation of the formation of 13 was obtained through independent synthesis via the reaction of the ruthenium precursor $\left[\mathrm{Cp}^{*} \mathrm{RuCl}\right]_{4}$ (4) with 8 equiv of benzylazide.

We propose that species $\mathbf{1 2}$ is a phosphazide complex generated by either the net insertion of azide into the bound phosphine or the reaction of a preformed phosphazide with the ruthenium complex, whereas species $\mathbf{1 3}$ is a tetraazametallacyclopentene complex generated by reaction of complex 6 a with 2 equiv of benzylazide, with the extrusion of 1 equiv of molecular nitrogen. Similar complexes have been previously reported in the literature. ${ }^{25-27}$

The reactivity of $\mathbf{6 a}$ with benzylazide was also examined under catalytic conditions (5 mol \% of catalyst). Variabletemperature ${ }^{1} \mathrm{H}$ NMR spectra of the reaction of $\mathrm{Cp} \mathrm{p}^{*} \mathrm{Ru}\left(\mathrm{P}^{i} \mathrm{Pr}_{3}\right)$ $\mathrm{Cl}$ with excess benzylazide are shown in Figure 6. The first spectrum at $233 \mathrm{~K}$ is a solution containing only $\mathrm{Cp} * \mathrm{Ru}\left(\mathrm{P}^{i} \mathrm{Pr}_{3}\right)$ Cl. Upon the addition of 20 equiv of benzylazide, slow formation of both complexes 12 and 13 was observed. Warming the solution to $273 \mathrm{~K}$ showed full conversion of $6 \mathrm{a}$ to 12 and 13. Additionally, at this temperature, a chemical shift at $\delta=4.8 \mathrm{ppm}$ begins to appear. This signal is assigned to the unbound phosphazide ${ }^{i} \operatorname{Pr}_{3} \mathrm{P}=\mathrm{N}_{3} \mathrm{Bn}$.

The top spectrum in Figure 6 corresponds to the addition of 20 equiv of phenylacetylene. Immediate formation of triazole 3a was observed. Interestingly, the signals attributable to species 13 were still present in the ${ }^{1} \mathrm{H}$ NMR spectrum, while the chemical shifts assigned to $\mathbf{1 2}$ disappeared. This suggests that complex $\mathbf{1 3}$ is inactive in catalysis and that $\mathbf{1 2}$ is a transient intermediate in the reaction cycle.

Catalysis reactions utilizing independently synthesized complexes 12 and 13, which were carried out under identical conditions to those described in Table 1 , confirmed the observations in the variable-temperature experiments. Reactions in which complex 13 was utilized showed $<1 \%$ conversion of $1 \mathbf{a}$ and $2 \mathrm{a}$ to $3 \mathrm{a}$, while reactions employing complex 12 


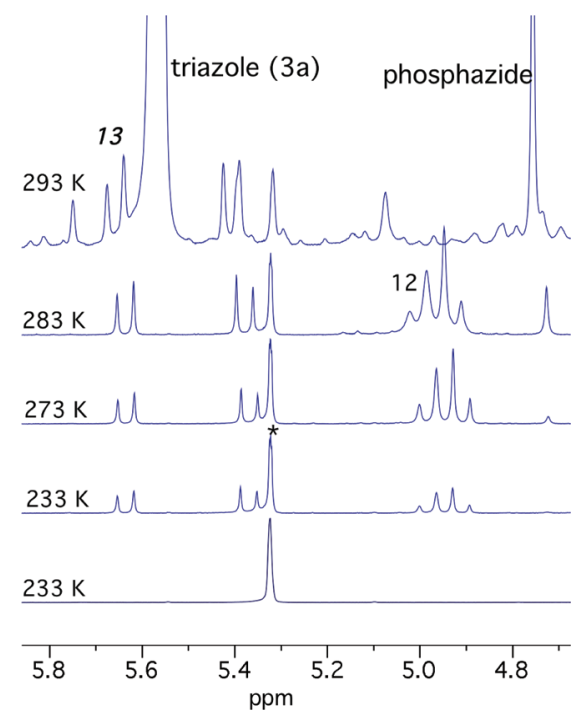

Figure 6. Selected region of variable-temperature ${ }^{1} \mathrm{H}$ NMR spectra of the reaction mixture of complex $\mathbf{6 a}$ and benzylazide (20 equiv) in $\mathrm{CD}_{2} \mathrm{Cl}_{2}$ (the signal denoted with * indicates protio impurities).

resulted in $92 \%$ conversion in $40 \mathrm{~min}$ at room temperature. The latter is similar to the activity found for complex $\mathbf{6 a}(89 \%$ conversion; see Table 1). Although this complex displays similar activity to that of $6 \mathrm{a}$, DFT computations suggest that complex $\mathbf{1 2}$ may play only a fleeting role in the catalytic cycle (vide infra).

Density Functional Theory (DFT) Results. DFT static calculations were performed at the GGA level with the Gaussian03 package, ${ }^{29}$ using the BP86 functional of Becke and Perdew. ${ }^{30}$ All energies reported correspond to free energies ( $\mathrm{kcal} / \mathrm{mol})$. Following the experimental strategy, computational efforts were applied to the reaction of $6 a$ with phenylacetylene (Scheme 3), then on the reactivity of $\mathbf{6 a}$ with benzylazide

Scheme 3. Free Energies ( $\mathrm{kcal} / \mathrm{mol}$ ) Corresponding to Intermediates and Transition States in the Reaction of 6a with Phenylacetylene ${ }^{a}$

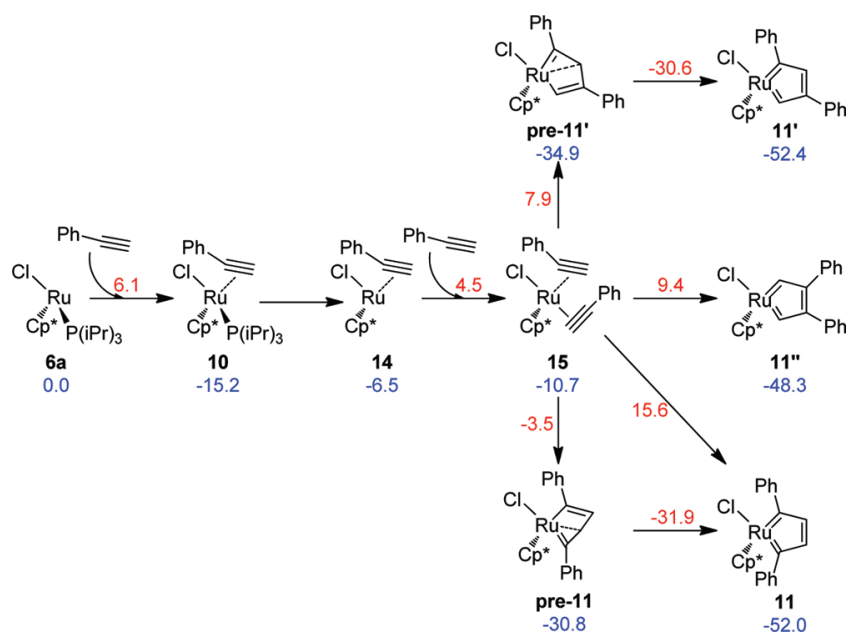

${ }^{a}$ Values in red above the arrows correspond to the energy of the transition states connecting the structures left and right of the arrow.

(Scheme 4), and finally we report on the reaction of 6a in the presence of both phenylacetylene and benzylazide (Scheme 5).
Reaction of $C p^{*} R u C l\left(P^{i} P_{3}\right)$ with Phenylacetylene. As shown in Scheme 3, the reaction of $\mathrm{Cp} * \mathrm{Ru}\left(\mathrm{P}^{i} \mathrm{Pr}_{3}\right) \mathrm{Cl}$ with excess phenyacetylene is predicted to result in the production of metallacycle 11 as initially predicted by Jia et al. ${ }^{23}$ Reaction pathways leading to three potential isomers of complex (11, 11', and 11"; see Scheme 3) were considered. Independent of the conformational isomer formed, the reaction initiates with $\eta^{2}$-coordination of one molecule of phenylacetylene to $\mathbf{6 a}$, leading to 10. $\eta^{2}$-Coordination of the phenylacetylene is predicted to be exothermic by $15.2 \mathrm{kcal} / \mathrm{mol}$ through a transition state located at $6.1 \mathrm{kcal} / \mathrm{mol}$. Dissociation of $\mathrm{P}^{i} \operatorname{Pr}_{3}$ from 10, leading to 14 , costs only $8.7 \mathrm{kcal} / \mathrm{mol}$, while coordination of a second phenylacetylene molecule leads to $15,10.7 \mathrm{kcal} / \mathrm{mol}$ below $\mathbf{6 a}+$ free phenylacetylene.

As cycloaddition is initiated, $\mathbf{1 5}$ is the branching point leading to formation of 11, 11', and 11". The most stable of the conformational isomers was calculated to be the 1,3 regioisomer 11', $52.4 \mathrm{kcal} / \mathrm{mol}$ below $\mathbf{6 a}+$ free phenylacetylene, followed by the 1,4 regioisomer 11 , only $0.4 \mathrm{kcal} /$ mol higher in energy, while the 2,3 regioisomer $11^{\prime \prime}$ is predicted to be less stable than $11^{\prime}$ by $4.1 \mathrm{kcal} / \mathrm{mol}$. Focusing on their formation, calculations indicate that $11^{\prime \prime}$ can be reached only via a single concerted step, through a transition state at $9.4 \mathrm{kcal} /$ mol. A single reaction pathway also leads to $11^{\prime}$, but in this case this is a two-step pathway with an intermediate, pre-11', at 34.9 $\mathrm{kcal} / \mathrm{mol}$ below $\mathbf{6 a}+$ free phenylacetylene, which is formed first through a transition state at $7.9 \mathrm{kcal} / \mathrm{mol}$. Intermediate pre-11' is characterized by a strong $\pi$-coordination between the $\mathrm{C} 2$ atom of the formed ring and the $\mathrm{Ru}$ center, leading to a rather strained structure. Dissociation of the C2 atom, through a transition state at $30.6 \mathrm{kcal} / \mathrm{mol}$, releases this strain, and the system collapses into regioisomer 11'.

Finally, for 11 we found that both the concerted and the twostep pathways are possible. The concerted transition state, at $15.6 \mathrm{kcal} / \mathrm{mol}$, is quite high in energy, which rules out this possibility with respect to the two-step pathway. In fact, the first transition state of the two-step pathway, leading to intermediate pre-11 at $30.8 \mathrm{kcal} / \mathrm{mol}$ below $\mathbf{6 a}+$ free phenylacetylene, is at $-3.5 \mathrm{kcal} / \mathrm{mol}$, and the opening of the strained pre-11 structure presents a negligible barrier in the gas phase and becomes barrierless when solvent effects are included. In agreement with previous insights, this analysis indicates that 11 should be the regioisomer formed preferentially, since branching from 15 through the two-step pathway toward 11, with a transition state at $-3.5 \mathrm{kcal} / \mathrm{mol}$, is highly preferred over any other reactivity. As a final remark, we were not able to find a two-step pathway leading to 11", probably due to steric congestion around the $\mathrm{Ph}$-substituted $\mathrm{C} 2$ and $\mathrm{C} 3$ atoms in the putative pre-11" intermediate, which makes the potential energy surface too flat to locate.

Reaction of $\mathrm{Cp} * \mathrm{RuCl}\left(\mathrm{P}^{\left.\mathrm{P} P \mathrm{Pr}_{3}\right)}\right.$ with Benzylazide. DFT computations detailing the reactivity of $6 \mathbf{a}$ with benzylazide are shown in Scheme 4. The reaction starts with coordination of benzylazide to $6 \mathrm{a}$ through the terminal $\mathrm{N}$ atom, leading to 16 with an energy gain of $11.4 \mathrm{kcal} / \mathrm{mol}$. Dissociation of $\mathrm{P}^{i} \operatorname{Pr}_{3}$ from 16, leading to 17 , costs $14.6 \mathrm{kcal} / \mathrm{mol}$. We also investigated if benzylazide could react with $\mathrm{P}^{i} \mathrm{Pr}_{3}$ to form the phosphazide species 12 , which lies $12.4 \mathrm{kcal} / \mathrm{mol}$ below $6 \mathrm{a}+$ benzylazide. Specifically, we examined formation of 12 via the pathways $6 \mathrm{a} \rightarrow 21 \rightarrow 12$ and $6 \mathrm{a} \rightarrow 16^{\prime} \rightarrow 21 \rightarrow 12$. The former pathway requires overcoming two barriers of 17.2 and $26.8 \mathrm{kcal} / \mathrm{mol}$, respectively. To reach intermediate $\mathbf{2 1}$ according to the second pathway requires overcoming two barriers, of 3.3 
Scheme 4. Energetics (kcal/mol) of the Reactivity of $6 a+$ Benzylazide $^{a}$

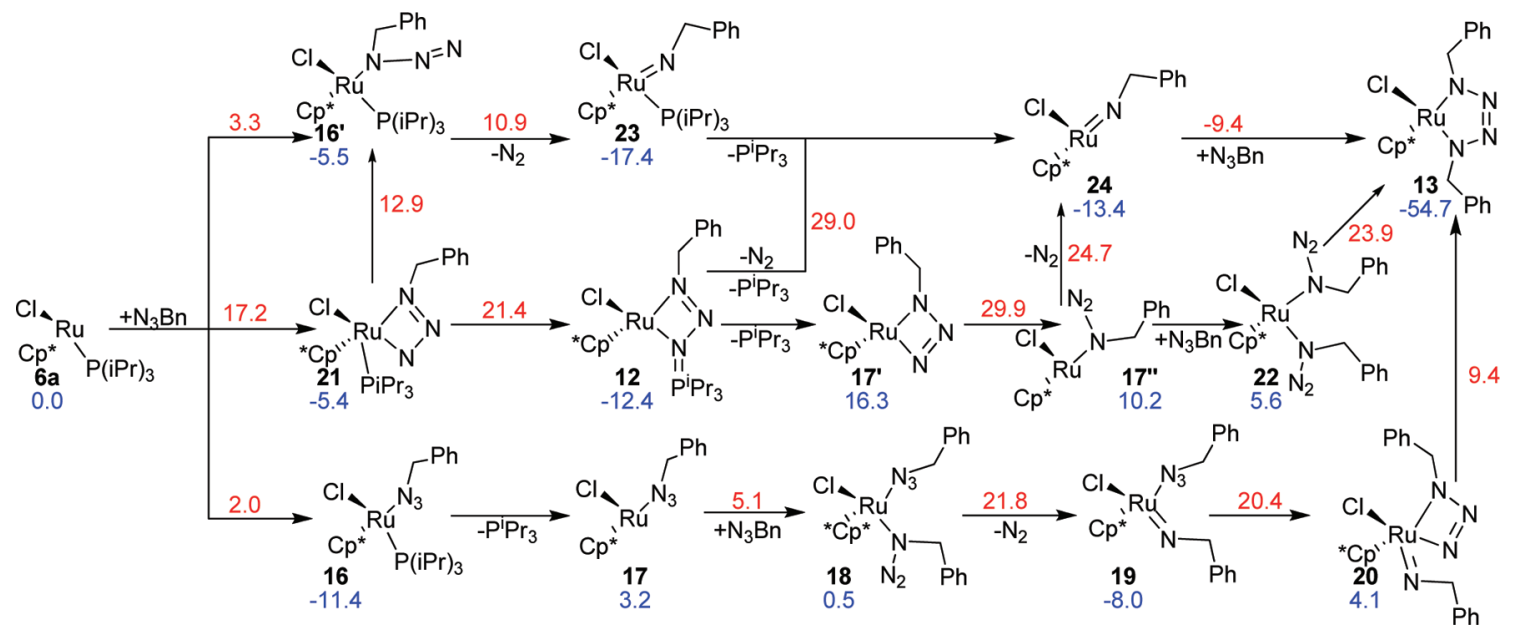

${ }^{a}$ All values correspond to free energies (values in red above the arrows correspond to the energy of the transition states connecting the structures left and right of the arrow).

Scheme 5. Free Energies (kcal/mol) Computed for Species Involved in Catalyst Activation

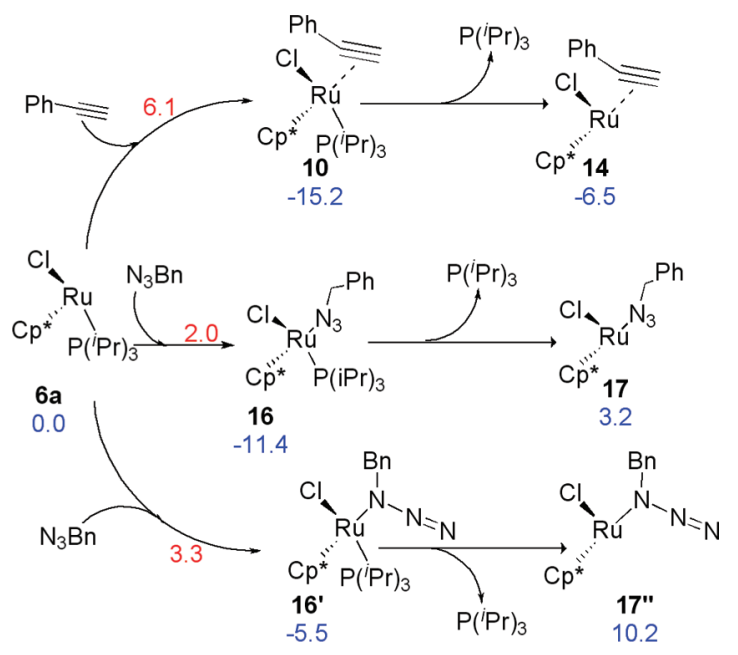

and $18.4 \mathrm{kcal} / \mathrm{mol}$, respectively. This indicates that formation of 21 , precursor of 12 , can occur along both the $6 a \rightarrow 21$ and $6 a$ $\rightarrow 16^{\prime} \rightarrow 21$ pathways. Nevertheless, calculations suggest that in the presence of the alkyne formation of the experimentally characterized species $\mathbf{1 2}$ is not favored, and thus it probably plays an incidental role in the $\mathbf{6 a} \rightarrow \mathbf{3} \mathbf{a}$ transformation.

Returning to the ${ }^{i} \operatorname{Pr}_{3}$ free intermediate 17, benzylazide coordination can occur in a variety of modes. The first involves a N1, N3 coordination of the azide moiety, structure $17^{\prime}$ at 16.3 $\mathrm{kcal} / \mathrm{mol}$ above $\mathbf{6 a}+$ benzylazide. Due to the high energy of 17', we also considered an alternative coordination of the azide through the internal $\mathrm{N}$ atom, i.e., structure $17^{\prime \prime}$ at $10.2 \mathrm{kcal} / \mathrm{mol}$ above $6 \mathrm{a}+$ benzylazide. Intermediate $17^{\prime \prime}$ can dissociate $\mathrm{N}_{2}$ through a transition state at $24.7 \mathrm{kcal} / \mathrm{mol}$, leading to species $\mathbf{2 4}, 13.4 \mathrm{kcal} / \mathrm{mol}$ below $\mathbf{6 a}+$ benzylazide. Then, reaction of $\mathbf{2 4}$ with another free benzylazide molecule, through a transition state at $-9.4 \mathrm{kcal} / \mathrm{mol}$, leads to the very stable tetraazametallacylopentene species 13, $54.7 \mathrm{kcal} / \mathrm{mol}$ below $6 \mathrm{a}+$ benzylazide. Species 24 can also be reached from species 16', through species 23. This is achieved by releasing first a $\mathrm{N}_{2}$ molecule from $16^{\prime}$ by overcoming a barrier of $16.4 \mathrm{kcal} / \mathrm{mol}$ followed by release of $\mathrm{P}^{i} \mathrm{Pr}_{3}$ from 23. On the other hand, species 13 can also be reached from 17" if an additional benzylazide molecule coordinates first to the $\mathrm{Ru}$ center, leading to intermediate $\mathbf{2 2}$, with an energy gain of $4.6 \mathrm{kcal} / \mathrm{mol} . \mathrm{N}_{2}$ release is then concerted with formation of the tetraazametallacylopentene ring, through a transition state at $23.9 \mathrm{kcal} / \mathrm{mol}$, leading again to 13. This indicates that $\mathrm{N}_{2}$ dissociation can occur either before the latter ring is formed, through intermediate $\mathbf{2 4}$, or concomittantly with ring formation, through intermediate 22, since the rate-limiting transition states, at 24.7 and $23.9 \mathrm{kcal} /$ mol, are very close in energy. However, 13 can also be reached from 17 by coordination of the second azide molecule through the internal $\mathrm{N}$ atom, leading to 18 , from which a $\mathrm{N}_{2}$ molecule can be released through a transition state at $21.8 \mathrm{kcal} / \mathrm{mol}$, and collapsing into intermediate 19. Cyclization through intermediate 20 finally leads to $\mathbf{1 3}$. The latter species displays similar $\mathrm{N}-\mathrm{N}$ bond distances $(1.318,1.318$, and $1.325 \AA$, respectively), thus delocalizing the electronic density of the previous $\mathrm{N}-\mathrm{N}$ double bonds.

Reaction of $\mathrm{Cp} * \mathrm{RuCl}\left(\mathrm{P}^{\left.\mathrm{P} P \mathrm{Pr}_{3}\right)}\right.$ with Phenylacetylene and Benzylazide. Gleaning information from the computations detailing individual reactions of phenylacetylene and benzylazide with 6a discussed above made clear that three potential pathways exist for catalyst activation. Shown in Scheme 5, in the presence of both phenylacetylene and benzylazide binding of benzylazide provides the lowest activation energy pathway. Ligation of the terminal nitrogen $\left(16, \Delta G^{\ddagger}=2.0 \mathrm{kcal} / \mathrm{mol}\right)$ is favored over that of the binding of the internal nitrogen $\left(\mathbf{1 6}^{\prime}\right)$ by $1.3 \mathrm{kcal} / \mathrm{mol}$. Although formation of $\mathrm{Cp} * \mathrm{RuCl}\left(\eta^{2}-\mathrm{HCCPh}\right)$ $\left(\mathrm{P}^{i} \mathrm{Pr}_{3}\right)(10)$ proceeds through a transition state located at 6.1 $\mathrm{kcal} / \mathrm{mol}$ higher than that of the starting material, formation of complex $\mathbf{1 0}$ was calculated to be more stable than the corresponding azide complexes 16 and 16'. Additionally, comparing the phosphine dissociation pathways between 10 , 16 , and $16^{\prime}$ it is evident that only 10 favors phosphine dissociation over that of the bound substrate. In other words, both complexes 16 and $16^{\prime}$ are predicted to possess lower energy pathways involving dissociation of the azide over that of the phosphine. In contrast, phosphine dissociation from $\mathbf{1 0}$ is endergonic by $8.7 \mathrm{kcal} / \mathrm{mol}$, while acetylene dissociation is calculated to proceed through a transition state of $21.3 \mathrm{kcal} /$ mol, thus trapping the stable intermediate $\mathbf{1 0}$ in an energy well. 
This coincides with experimental results, as complex 10 was observed by NMR spectrometry at low temperatures even when azide addition to $\mathbf{6 a}$ precluded acetylene addition.

Once again, due to the nature of the substrates, several possible scenarios were examined for the steps following formation of complex 14. Shown in Scheme 6 are the potential

Scheme 6. Free Energy of Potential Pathways Leading from $\mathrm{Cp} * \operatorname{RuCl}\left(\eta^{2}-\mathrm{HCCPh}\right)\left(\mathrm{P}^{i} \operatorname{Pr}_{3}\right)(14)$ in the Presence of Both Phenylacetylene and Benzylazide ${ }^{a}$

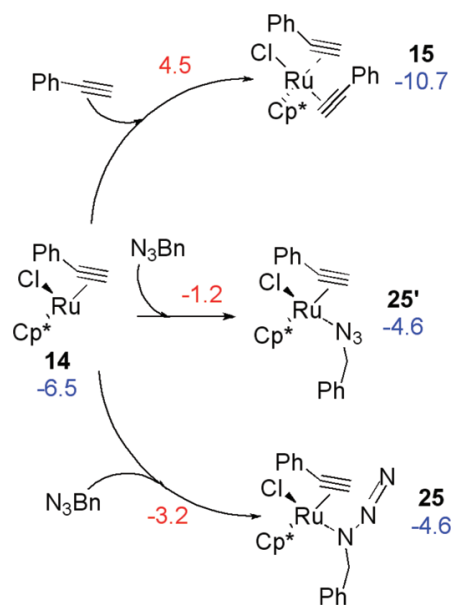

${ }^{a}$ All energies relative to $\mathbf{6 a}+\mathrm{N}_{3} \mathrm{Bn}+\mathrm{HCCPh}$. Energies in red represent transition-state free energies; energies in blue, those of intermediates.

pathways forward in the presence of both phenylacetylene and benzylazide. Coordination of a second molecule of phenylacetylene, ultimately leading to deactivation of the catalyst through formation of complex 11, was calculated to have the highest energy barrier $\left(\Delta G^{\ddagger}=11 \mathrm{kcal} / \mathrm{mol}\right)$. Azide coordination barriers were calculated to be much lower, with ligation of the internal nitrogen predicted to ultimately possess the lowest barrier $\left(\Delta \Delta G^{\ddagger}=2.0 \mathrm{kcal} / \mathrm{mol}\right)$ than terminal $\mathrm{N}$ coordination of the azide. Internal $\mathrm{N}$-coordination of a molecule of azide is favored over a second molecule of phenylacetylene by $7.7 \mathrm{kcal} / \mathrm{mol}$.

Lin, Jia, Fokin, et al. have previously performed computations detailing the mechanistic aspects of triazole formation from the model complex $\mathrm{CpRuCl}\left(\eta^{2}-\mathrm{HCCMe}\right)\left(\alpha-\mathrm{N}-\mathrm{N}_{3} \mathrm{Me}\right)$, similar to complex 25. ${ }^{6 \mathrm{c}}$ Our efforts using complete molecules support those initially found using the model complex. Although slight differences in the calculated free energies are present, these are suspected to mainly be the result of a combination of increased sterics of the substrates and possibly stabilization of intermediates through conjugation with the aryl rings or phenyl acetylene and benzylazide.

Figure 7 shows calculated free energies of the species involved in triazole formation once both azide and acetylene substrates have been coordinated to the $\mathrm{Ru}$ metal center. Graphical representations of these species as determined by DFT calculations are shown in Figure 8. Triazole formation from 25 is rather a dynamic process. Initiation of $\mathrm{C}-\mathrm{N}$ bond formation between the azide with the alkyne occurs through a transition state at $-4.3 \mathrm{kcal} / \mathrm{mol}\left(\Delta G^{\ddagger}=0.3 \mathrm{kcal} / \mathrm{mol}\right)$, and the system collapses into intermediate $26,34.3 \mathrm{kcal} / \mathrm{mol}$ below $\mathbf{6 a}$ + free phenylacetylene and benzylazide. The $\mathrm{C}-\mathrm{N}$ bond distance is calculated to be $1.446 \AA$. At this point the azide

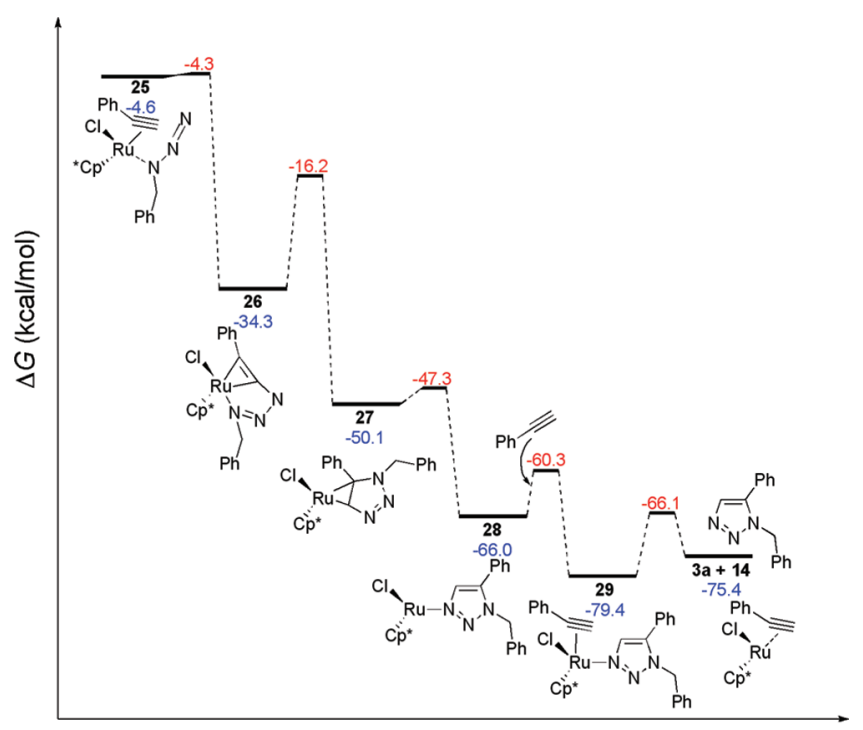

Reaction Coordinate

Figure 7. Free energies $(\mathrm{kcal} / \mathrm{mol})$ of triazole formation beginning from complex 25. All free energies in $\mathrm{kcal} / \mathrm{mol}$ are relative to $\mathrm{Cp} * \mathrm{RuCl}\left(\mathrm{P}^{i} \mathrm{Pr}_{3}\right)+\mathrm{HCCPh}+\mathrm{N}_{3} \mathrm{CH}_{2} \mathrm{Ph}=0.0 \mathrm{kcal} / \mathrm{mol}$. Values in red above the arrows correspond to the energy of the transition states connecting the structures left and right of the arrow.

moiety rotates down into an orientation in which it is nearly coplanar with the CC of the bound acetylene, as shown in Figure 8. Oxidative coupling facilitates the second $\mathrm{C}-\mathrm{N}$ bond formation and occurs through a transition state at $-16.2 \mathrm{kcal} /$ mol, which corresponds to a free energy barrier of $18.1 \mathrm{kcal} /$ mol from 26, in agreement with previous insights into this reaction. ${ }^{6 c, 9 b}$ This process leads to a previously unidentified intermediate, $\mathbf{2 7}$, in which the triazole is coordinated to the $\mathrm{Ru}$ metal center through a matallacyclopropane. Dissociation of the 1-C of the triazole through intermediate $\mathbf{2 7 - 2 8}$ is accompanied by an increase in $\mathrm{C}=\mathrm{C}$ bonding characteristics denoted by a shortening of the $\mathrm{C}-\mathrm{C}$ bond from $1.433 \AA$ in complex 27 to $1.395 \AA$ in complex 28 , as well as the shortening of the C1-N5 bond of the triazole, decreasing from $1.399 \AA$ to $1.271 \AA$ A. Only a relatively small energy barrier exists for the isomerization of the $\mathrm{Ru}-\mathrm{C}$-based triazole complex 27 to the more stable $\mathrm{Ru}-\mathrm{N}$ based triazole bond in complex 28 . The coordinated triazole-Ru complex was calculated to be $66.0 \mathrm{kcal} / \mathrm{mol}$ below $\mathbf{6 a}+$ free phenylacetylene and benzylazide.

Dissociation of the coordinated triazole from complex $\mathbf{2 8}$ was calculated to be aided by the $\eta^{2}$ coordination of the second molecule of phenylacetylene, corresponding to a free energy barrier of $5.7 \mathrm{kcal} / \mathrm{mol}$. Ultimately this results in the formation of complex 29. Coordination of phenylacetylene to $\mathbf{2 8}$ is predicted to be exothermic by $13.4 \mathrm{kcal} / \mathrm{mol}$. Regeneration of complex 14 from 29 through triazole dissociation requires a free energy barrier of $13.1 \mathrm{kcal} / \mathrm{mol}$, only slightly larger than the barrier associated with dissociation of $\mathrm{P}^{i} \mathrm{Pr}_{3}$ from complex $10\left(\Delta G^{\dagger}=8.7 \mathrm{kcal} / \mathrm{mol}\right)$.

Overall, our analysis suggests that catalyst activation should proceed through coordination of phenylacetylene over that of benzylazide coordination. Rationalization of this stems from complex $10\left\{\mathrm{Cp} * \operatorname{RuCl}\left(\eta^{2}-\mathrm{HCCPh}\right)\left(\mathrm{P}^{i} \mathrm{Pr}_{3}\right)\right\}$ acting as an energy well in which phosphine dissociation is favored over substrate dissociation. Furthermore, our calculations suggest that pathways leading to catalyst deactivation, through formation of either complex 11 or 13, should be competitive 


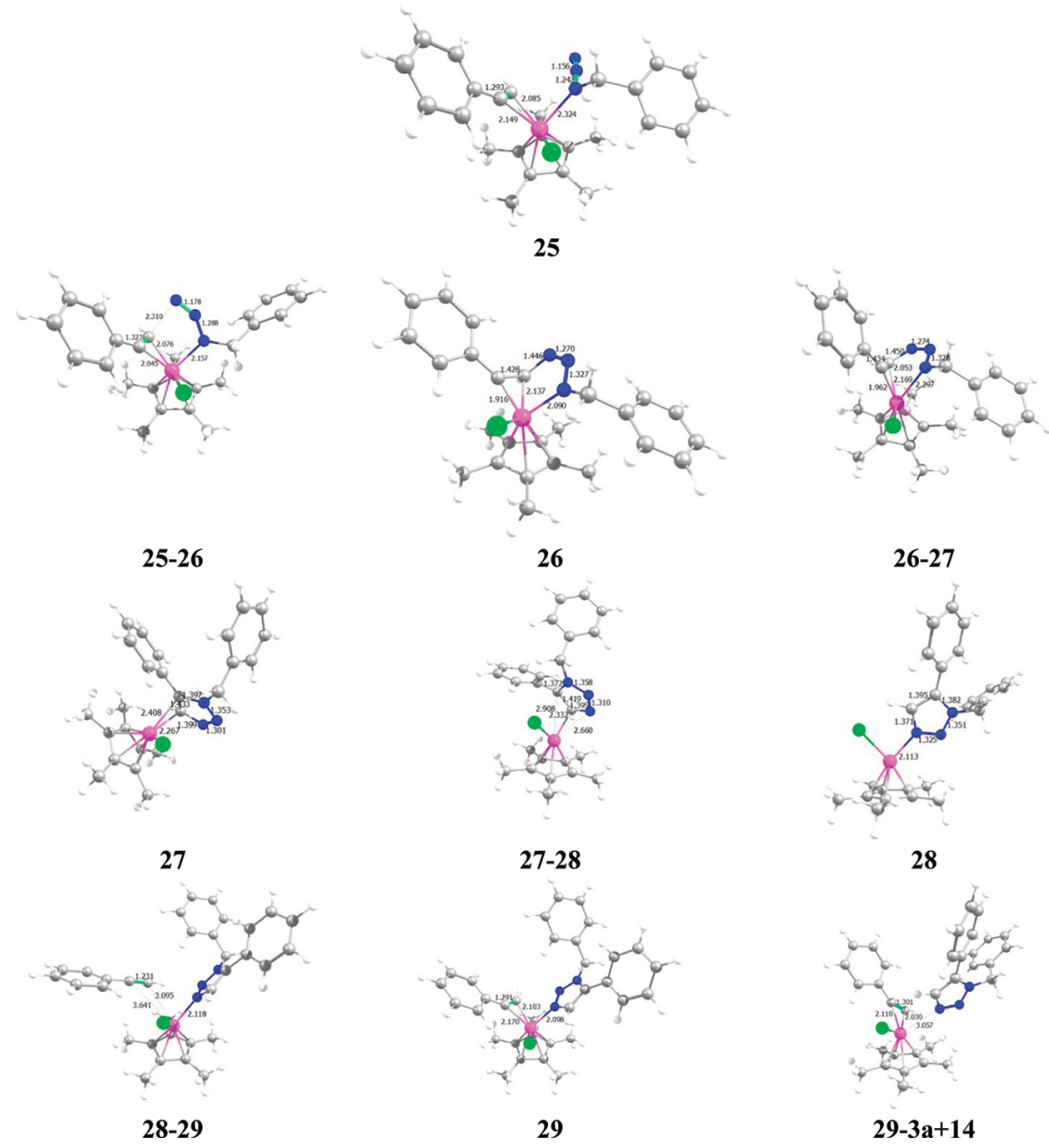

Figure 8. Selected structural parameters (in $\AA$ ) calculated for the species involved in RuAAC. Larger graphics are placed in the Supporting Information.

with triazole formation under the circumstances where either the acetylene or azide substrate is present in a large excess relative to the other. The overall mechanism determined herein has been found to be consistent with previous analysis ${ }^{6 c, 9 b}$ and supports the energy profile reported by Fokin et al., which was obtained through the utilization of a model system.

RuACC Mechanism. Uniting computational and experimental investigations, the overall proposed mechanism for triazole formation mediated by the $\mathrm{Cp} * \mathrm{RuCl}$ moiety through activation of the precatalyst $\mathrm{Cp} * \mathrm{RuCl}\left(\mathrm{P}^{i} \mathrm{Pr}_{3}\right)$ is shown in Scheme 7. Initial side-on coordination of phenylacetylene leads to the experimentally observed $\mathrm{Cp} * \mathrm{RuCl}\left(\eta^{2}-\mathrm{HCCPh}\right)\left(\mathrm{P}^{i} \mathrm{Pr}_{3}\right)$ (10). Computations suggest that dissociation of the phosphine from $\mathbf{1 0}$ is favored over phenylacetylene dissociation. Ligation of benzylazide through the internal nitrogen leads to formation of complex 25. Nucleophilic attack of the terminal acetylene $\mathrm{CH}$ on the terminal nitrogen of the azide proceeds through a nearly barrierless process $\left(\Delta G^{\ddagger}=0.3 \mathrm{kcal} / \mathrm{mol}\right) . \mathrm{C}-\mathrm{N}$ oxidative coupling in complex 26 results in cyclization, ultimately leading to N-bound triazole complex 28. Following formation of $\mathrm{Ru}-$ triazole complex 28, catalyst regeneration begins with coordination of an additional molecule of phenylacetylene. Release of free triazole from complex 29 results in restoration of the $\mathrm{Cp} * \mathrm{RuCl}\left(\eta^{2}-\mathrm{HCCPh}\right)$ species. Triazole formation is predicted to be exothermic by $68.9 \mathrm{kcal} / \mathrm{mol}$ and likely drives the reaction.

\section{CONCLUSIONS}

The behavior of the 16-electron ruthenium complexes $\mathrm{Cp} * \mathrm{Ru}(\mathrm{L}) \mathrm{X}\left(\mathrm{L}=\mathrm{P}^{i} \mathrm{Pr}_{3}, \mathrm{PCy}_{3}, \mathrm{IAd}, \mathrm{IPr}\right.$ ICy, IMes; $\mathrm{X}=\mathrm{Cl}$, $\mathrm{OCH}_{2} \mathrm{CF}_{3}$ ) was examined in the RuAAC reaction. The phosphines were found to result in more efficient catalysts over the corresponding NHC complexes. Use of the catalyst $\mathrm{Cp} * \mathrm{Ru}\left(\mathrm{P}^{i} \mathrm{Pr}_{3}\right)\left(\mathrm{OCH}_{2} \mathrm{CF}_{3}\right)$ resulted in only $2 \%$ conversion, in stark contrast to $\mathrm{Cp}{ }^{*} \mathrm{Ru}\left(\mathrm{P}^{i} \mathrm{Pr}_{3}\right) \mathrm{Cl}$, which was found to be the optimal catalyst within the study. Additionally, $\mathrm{Cp} * \mathrm{Ru}\left(\mathrm{P}^{i} \mathrm{Pr}_{3}\right) \mathrm{Cl}$ displayed improved performance with respect to the 18electron ruthenium catalysts, ${ }^{6}$ allowing the production of several triazole products under milder conditions and shorter reaction times. Moreover, a number of new 1,5-disubstitued 1,2,3-triazoles were produced with high yields.

As already reported for the 18-electron ruthenium catalysts, complex 6a showed a high reactivity with 1,1-disubstituted propargylic alcohols. Interestingly, we found that, in general, electron-donating groups on the carbon at the $\alpha$ position to the triple bond of the alkyne substrate promote high reactivity. As a matter of fact, these properly substituted alkynes were found to be extremely active in the reaction with benzyl- and phenylazide.

Mechanistic studies revealed possible pitfalls in the catalytic cycle along with the identification of $\mathrm{Cp} * \mathrm{Ru}\left(\eta^{2}-\mathrm{HCCPh}\right)$ $\left(\mathrm{P}^{i} \mathrm{Pr}_{3}\right) \mathrm{Cl}(10)$ and bound phosphazide complex $\mathrm{Cp} * \mathrm{Ru}\left(\kappa^{2}-\right.$ $\left.\mathrm{N}_{3} \mathrm{Bn}\right)\left(\mathrm{P}^{i} \mathrm{Pr}_{3}\right) \mathrm{Cl}$ (12). Single crystals suitable for XRD unambiguously clarified the atom connectivity in the latter complex. 
Scheme 7. Proposed Precatalyst Activation and Subsequent Catalytic Cycle in the RuAAC of Benzylazide with Phenylacetylene $^{a}$

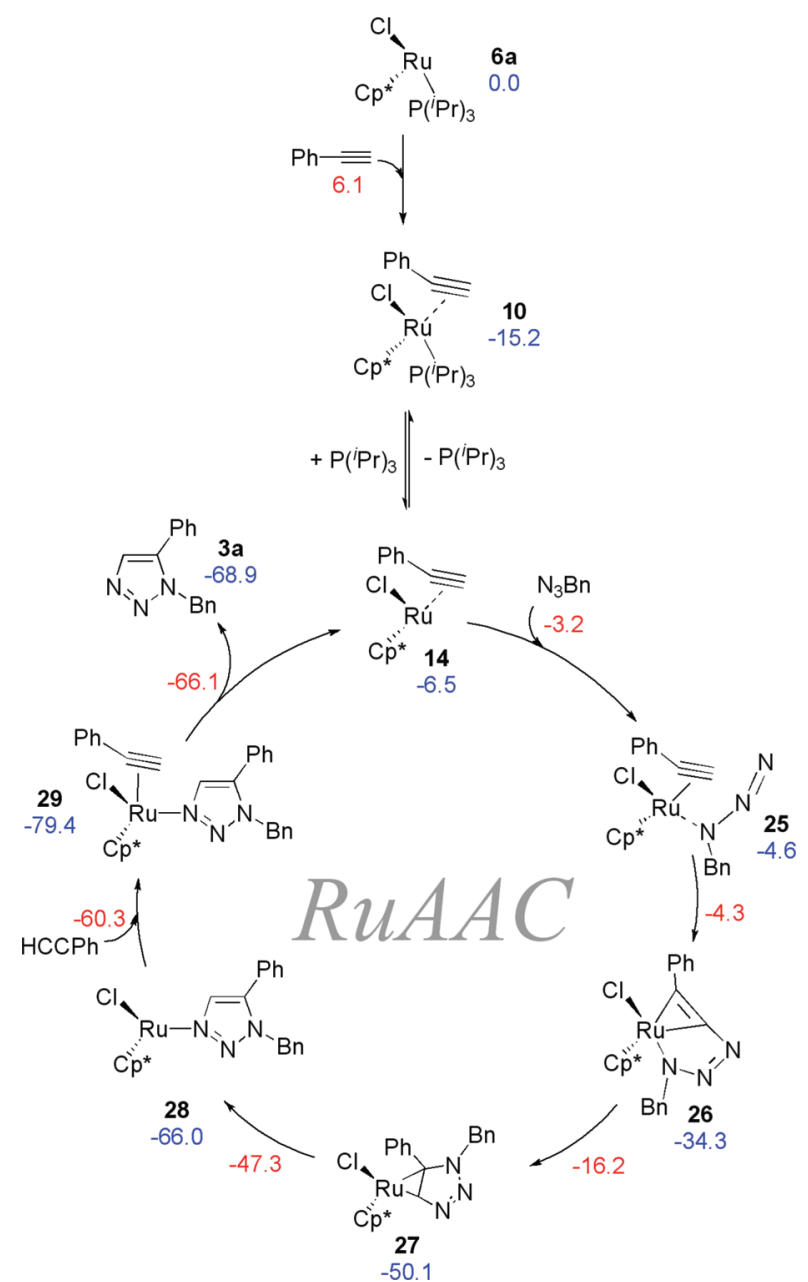

${ }^{a}$ Numbers in blue coorespond to free energies ( $\mathrm{kcal} / \mathrm{mol}$ ) of intermediates, and numbers in red correspond to free energies $(\mathrm{kcal} / \mathrm{mol})$ of the corresponding transition states.

Experimental results and DFT computations are in agreement and suggest that acetylene binding precedes azide coordination. Catalyst initiation was proposed to occur through the formation $\mathrm{Cp} * \mathrm{Ru}\left(\eta^{2}-\mathrm{HCCPh}\right)\left(\mathrm{P}^{i} \mathrm{Pr}_{3}\right) \mathrm{Cl}(10)$ followed by phosphine loss. DFT computations calculate coordination of a molecule of $\mathrm{N}_{3} \mathrm{Bn}$ to $\mathrm{Cp} * \mathrm{Ru}\left(\eta^{2}-\mathrm{HCCPh}\right) \mathrm{Cl}$ through the internal nitrogen to be favored over coordination of a second molecule of HCCPh by $7.7 \mathrm{kcal} / \mathrm{mol}$. DFT calculations also resulted in locating the previously unidentified intermediate 27 , in which the formed triazole is bound to the Ru metal center in a $\mathrm{C}-\mathrm{Ru}-\mathrm{C}$ metallacyclopropane fashion, which ultimately isomerizes to the $\mathrm{N}$-bound triazole $\mathrm{Ru}$ species $\mathbf{2 8}$.

\section{EXPERIMENTAL SECTION}

General Considerations. All reagents and solvents were purchased from commercial suppliers and used as received. The catalysts were synthesized in an MBraun glovebox containing dry argon and less than $1 \mathrm{ppm}$ oxygen according to previously described procedures. Complexes $1-7$ were synthesized according to previously described procedures. ${ }^{10,14,15}$ Flash column chromatography was performed on silica gel $60(230-400 \mathrm{mesh}) .{ }^{1} \mathrm{H},{ }^{13} \mathrm{C}$, and ${ }^{31} \mathrm{P} \mathrm{NMR}$ spectra were recorded on either a Bruker Avance $300 \mathrm{MHz}$ or Bruker
Avance II $400 \mathrm{MHz}$ spectrometer. Solvents were of puriss. grade and used as received. Spectra were referenced to $\mathrm{CD}_{2} \mathrm{Cl}_{2}$ at $c 5.32\left({ }^{13} \mathrm{C}, \delta\right.$ $54.00)$ or $\mathrm{CDCl}_{3}$ at $\delta 7.26\left({ }^{13} \mathrm{C}, \delta 77.23\right) \mathrm{ppm}$. Gas chromatography (GC) was performed on an Agilent $6890 \mathrm{~N}$ gas chromatograph.

General Procedure for the [3+2] Cycloaddition of Azides and Terminal Alkynes. In a vial fitted with a screw cap, azide (0.5 $\mathrm{mmol})$ and alkyne $(0.52 \mathrm{mmol})$ were added to a solution of catalyst 1 ( $1 \mathrm{~mol} \%)$ in organic solvent. The solution was stirred at a given temperature for a period of time indicated in Scheme 2. The reaction was monitored by GC analysis of aliquots. In most cases the azide was completely consumed at the end of the reaction. The solvent was removed under vacuum, and the product was purified by silica gel chromatography. The unreacted alkyne and traces of side products were first eluted out with hexane, followed by 1:1 hexane/ether. The pure 1,5-disubstituted triazole product was then obtained by elution with ether or ethyl acetate.

Computational Details. The DFT static calculations were performed at the GGA level with the Gaussian03 package, ${ }^{29}$ using the BP86 functional of Becke and Perdew. ${ }^{30}$ The electronic configuration of the molecular systems was described with the standard split-valence basis set with a polarization function of Ahlrichs and co-workers for $\mathrm{H}, \mathrm{C}, \mathrm{N}, \mathrm{O}, \mathrm{P}$, and $\mathrm{Cl}$ (SVP keyword in Gaussian03). ${ }^{31}$ For $\mathrm{Ru}$ we used the small-core, quasi-relativistic Stuttgart/Dresden effective core potential, with an associated $(8 \mathrm{~s} 7 \mathrm{p} 6 \mathrm{~d}) /[6 \mathrm{~s} 5 \mathrm{p} 3 \mathrm{~d}]$ valence basis set contracted according to a $(311111 / 22111 / 411)$ scheme (standard SDD keywords in Gaussian03). ${ }^{32}$ The geometry optimizations were performed without symmetry constraints, and the characterization of the located stationary points was performed by analytical frequency calculations. Solvent effects including contributions of non-electrostatic terms have been estimated by single-point calculations on the gas phase optimized structures, ${ }^{33}$ based on the polarizable continuous solvation model using $\mathrm{CH}_{2} \mathrm{Cl}_{2}$ as the solvent. ${ }^{34}$

\section{ASSOCIATED CONTENT}

S Supporting Information

Analytical and spectral characterization data, Cartesian coordinates and 3D view for all DFT-optimized structures, and an extension of Scheme 4. This material is available free of charge via the Internet at http://pubs.acs.org.

\section{AUTHOR INFORMATION}

\section{Corresponding Author}

*E-mail: snolan@st-andrews.ac.uk.

\section{ACKNOWLEDGMENTS}

S.P.N. would like to thank the ERC (Advanced Researcher Award FUNCAT) for financial support. A.P. thanks the Spanish MICINN for a Ramón y Cajal contract (ref RYC2009-05226) and the European Commission for a Career Integration Grant (CIG09-GA-2011-293900). L.C. and A.P. thank the HPC team of Enea (www.enea.it) for using the ENEA-GRID and the HPC facilities CRESCO (www.cresco. enea.it) in Portici, Italy. M.L. acknowledges Salerno Province and the University of Salerno for supporting her stay at the University of St Andrews (International Mobility Scholarship 2009). S.P.N. is a Royal Society Wolfson Research Merit Award holder.

\section{REFERENCES}

(1) (a) Gilchrist, T. L.; Gymer, G. E. Adv. Heterocycl. Chem. 1974, 16, 33-85. (b) Finley, K. T. Triazoles: 1,2,3. In The Chemistry of Heterocyclic Compounds; Weissberger, A., Taylor, C. E., Eds.; John Wiley \& Sons: New York, 1980. (c) Katritzky, A. R.; Zhang, Y.; Singh, S. K. Heterocyles 2003, 60, 1225-1239. (d) Krivopalov, V. P.; Shkurko, O. P. Russ. Chem. Rev. 2005, 74, 339-379. For therapeutic activities, 
see: (e) Buckle, D. R.; Rockell, C. J. M.; Smith, H.; Spicer, B. A. J. Med. Chem. 1986, 29, 2262-2267. (f) Alvarez, R.; Velazquez, S.; San-Felix, A.; Aquaro, S.; De Clercq, E.; Perno, C. F.; Karlsson, A.; Balzarini, J.; Camarasa, M. J. J. Med. Chem. 1994, 37, 4185-4194. (g) Chen, M. D.; Lu, S. J.; Yuag, G. P.; Yang, S. Y.; Du, X. L. Heterocycl. Commun. 2000, 6, 421-426. (h) Genin, M. J.; Allwine, D. A.; Anderson, D. J.; Barbachyn, M. R.; Emmert, D. E.; Garmon, S. A.; Graber, D. R.; Grega, K. C.; Hester, J. B.; Hutchinson, D. K.; Morris, J.; Reischer, R. J.; Ford, C. W.; Zurenko, G. E.; Hamel, J. C.; Schaadt, R. D.; Stapert, D.; Yagi, B. H. J. Med. Chem. 2000, 43, 953-970.

(2) (a) Huisgen, R. Angew. Chem., Int. Ed. 1963, 2, 565-598. (b) Huisgen, R. 1,3-Dipolar Cycloadditional Chemistry; Padwa, A., Ed.; Wiley: New York, 1984.

(3) Wang, Q.; Chittaboina, S.; Barnhill, H. N. Lett. Org. Chem. 2005, 2, 293-301.

(4) Tornøe, C. W.; Christensen, C.; Meldal, M. J. Org. Chem. 2002, 67, 3057-3064.

(5) Rostovtsev, V. V.; Green, L. G.; Fokin, V. V.; Sharpless, K. B. Angew. Chem., Int. Ed. 2002, 41, 2596-2599.

(6) (a) Zhang, L.; Chen, X.; Xue, P.; Sun, H. H. Y.; Williams, I. D.; Sharpless, K. B.; Fokin, V. V.; Jia, G. J. Am. Chem. Soc. 2005, 127, 15998-15999. (b) Rasmussen, L. K.; Boren, B. C.; Fokin, V. V. Org. Lett. 2007, 9, 5337-5339. (c) Boren, B. C.; Narayan, S.; Rasmussen, L. K.; Zhang, L.; Zhao, H.; Lin, Z.; Jia, G.; Fokin, V. V. J. Am. Chem. Soc. 2008, 130, 8923-8930.

(7) Kolb, H. C.; Finn, M. G.; Sharpless, K. B. Angew. Chem., Int. Ed. 2001, 40, 2004-2021.

(8) (a) Meldal, M.; Tornøe, C. W. Chem. Rev. 2008, 108, 29523015. (b) Feldman, A. K.; Colasson, B.; Sharpless, K. B.; Fokin, V. V. J. Am. Chem. Soc. 2005, 127, 13444-13445. (c) Rodionov, V. O.; Presolski, S. I.; Díaz, D.; Fokin, V. V.; Finn, M. G. J. Am. Chem. Soc. 2007, 129, 12705-12712. (d) Dutta, B.; Curchod, B. F. E.; Campomanes, P.; Solari, E.; Scopelliti, R.; Rothlisberger, U.; Severin, K. Chem.-Eur. J. 2010, 16, 8400-8409.

(9) (a) Majireck, M. M.; Weinreb, S. M. J. Org. Chem. 2006, 71, 8680-8683. (b) Hou, D.-R.; Kuan, T.-C.; Li, Y.-K.; Lee, R.; Huang, K.-W. Tetrahedron 2010, 66, 9415-9420. (c) Zhang, C. T.; Zhang, X.; Qing, F.-L. Tetrahedron Lett. 2008, 49, 3927-3930. (d) Oppilliart, S.; Mousseau, G.; Zhang, L.; Jia, G.; Thuery, P.; Rousseau, B.; Cintrat, J. C. Tetrahedron 2007, 63, 8094-8098. (e) Yamamoto, Y.; Kinpara, K.; Nishiyama, H.; Itoh, K. Adv. Synth. Catal. 2005, 347, 1913-1916.

(10) NHC-copper complexeswere found highly efficient catalysts for the CuAAC reaction. See,for example: Díez- González, S.; Nolan, S. P. Angew. Chem., Int. Ed. 2008, 47, 8881-8884.

(11) (a) Huang, J.; Schanz, H.-J.; Stevens, E. D.; Nolan, S. P. Organometallics 1999, 18, 2370-2375. (b) Campion, B. K.; Heyn, R. H.; Tilley, T. D. J. Chem. Soc., Chem. Commun. 1988, 278-280. (c) Johnson, T. J.; Folting, K.; Streib, W. E.; Martin, J. D.; Huffman, J. C.; Jackson, S. A.; Eisenstein, O.; Caulton, K. G. Inorg. Chem. 1995, 34, 488-499.

(12) (a) Luo, L.; Nolan, S. P. Organometallics 1994, 13, 4781-4786. (b) Li, C.; Luo, L.; Nolan, S. P.; Marshall, W.; Fagan, P. J. Organometallics 1996, 15, 3456-3462.

(13) (a) Poater, A.; Cosenza, B.; Correa, A.; Giudice, S.; Ragone, F.; Scarano, V.; Cavallo, L. Eur. J. Inorg. Chem. 2009, 1759-1766. (b) Jacobsen, H.; Correa, A.; Poater, A.; Costabile, C.; Cavallo, L. Coord. Chem. Rev. 2009, 253, 687-703. (c) Poater, A.; Ragone, F.; Giudice, S.; Costabile, C.; Dorta, R.; Nolan, S. P.; Cavallo, L. Organometallics 2008, 27, 2679-2681. (d) Ragone, F.; Poater, A.; Cavallo, L. J. Am. Chem. Soc. 2010, 132, 4249-4258. (e) Poater, A.; Cavallo, L. Dalton Trans. 2009, 8878-8883. (f) Clavier, H.; Nolan, S. P. Chem. Commun. 2010, 46, 841-861. (g) Luan, X.; Mariz, R.; Gatti, M.; Costabile, C.; Poater, A.; Cavallo, L.; Linden, A.; Dorta, R. J. Am. Chem. Soc. 2008, 130, 6848-6858. (h) Credendino, R.; Poater, A.; Ragone, F.; Cavallo, L. Catal. Sci. Technol. 2011, 1, 1287-1297.

(14) Hiller, A. C.; Sommer, W. J.; Yong, B. S.; Petersen, J. L.; Cavallo, L.; Nolan, S. P. Organometallics 2003, 22, 4322-4326.
(15) (a) Jafarpour, L.; Stevens, E. D.; Nolan, S. P. J. Organomet. Chem. 2000, 606, 49-54. (b) Huang, J.; Stevens, E. D.; Nolan, S. P.; Petersen, J. L. J. Am. Chem. Soc. 1999, 121, 2674-2678.

(16) Johnson, T. J.; Folting, K.; Strieb, W. E.; Martin, J. D.; Huffman, J. C.; Jackson, S. A.; Eisenstein, O.; Caulton, K. G. Inorg. Chem. 1995, 34, 488-499.

(17) Tam, A.; Arnold, U.; Soellner, M. B.; Raines, R. T. J. Am. Chem. Soc. 2007, 129, 12670-12671.

(18) Complete ${ }^{1} \mathrm{H}$ spectra and accompanying ${ }^{31} \mathrm{P}$ NMR spectra are given in Supporting Information Figures S1 and S2.

(19) See Supporting Information for NMR spectra characterization of $\eta^{2}$-HCCPh Ru complex 10.

(20) Complete ${ }^{1} \mathrm{H}$ spectra and accompanying ${ }^{31} \mathrm{P}$ NMR spectra are given in Supporting Information Figures S3 and S4.

(21) Kirchner, K.; Calhorda, M. J.; Schmid, R.; Veiros, L. F. J. Am. Chem. Soc. 2003, 125, 11721-11729, and reference therein.

(22) (a) Albers, M. O.; de Waal, D. J. A.; Liles, D. C.; Robinson, D. J.; Singleton, E.; Wiege, M. B. J. Chem. Soc., Chem. Commun. 1986, 1680-1682. (b) Campion, B. K.; Heyn, R. H.; Don Tilley, T. Organometallics 1990, 9, 1106-1112.

(23) Zhang, L.; Sung, H. H.-Y.; Williams, I. D.; Lin, Z.; Jia, G. Organometallics 2008, 27, 5122-5129.

(24) Staudinger, H.; Meyer, J. Helv. Chim. Acta 1919, 2, 635-646.

(25) (a) Cenini, S.; Gallo, E.; Caselli, A.; Ragaini, F.; Fantauzzi, S.; Piangiolino, C. Coord. Chem. Rev. 2006, 250, 1234-1253. (b) Bebbington, M. W. P.; Bourissou, D. Coord. Chem. Rev. 2009, 253, 1248-1261. (c) Hillhouse, G. L.; Goeden, G. V.; Haymore, B. L. Inorg. Chem. 1982, 21, 2064-2071. (d) Fortman, G. C.; Captain, B.; Hoff, C. D. Organometallics 2009, 28, 3587-3590. (e) Liu, B.; Cui, D. Dalton Trans. 2009, 550-556.

(26) Danopoulos, A. A.; Hay-Motherwell, R. S.; Wilkinson, G.; Cafferkey, S. M.; Sweet T. K. N. Hursthouse, M. B. J. Chem. Soc., Dalton Trans. 1997, 3177-3184.

(27) Michelman, R. I.; Bergman, R. G.; Andersen, R. A. Organometallics 1993, 12, 2741-2751.

(28) CCDC 820903 (17) contains the supplementary crystallographic data for this contribution. These data can be obtained free of charge from The Cambridge Crystallographic Data Centre via www. ccdc.cam.ac.uk/data_request/cif.

(29) Frisch, M. J.;et al. Gaussian03; Gaussian, Inc.: Pittsburgh, PA, 2003.

(30) (a) Becke, A. Phys. Rev. A 1988, 38, 3098-3100. (b) Perdew, J. P. Phys. Rev. $B$ 1986, 33, 8822-8824. (c) Perdew, J. P. Phys. Rev. B 1986, 34, 7406-7406.

(31) Schaefer, A.; Horn, H.; Ahlrichs, R. J. Chem. Phys. 1992, 97, 2571-2577.

(32) Kuechle, W.; Dolg, M.; Stoll, H.; Preuss, H. J. Chem. Phys. 1994, $100,7535-7542$.

(33) (a) Poater, A.; Ragone, F.; Correa, A.; Cavallo, L. J. Am. Chem. Soc. 2009, 131, 9000-9006. (b) Poater, A.; Cavallo, L. J. Mol. Catal. A 2010, 324, 75-79. (c) Bosson, J.; Poater, A.; Cavallo, L.; Nolan, S. P. J. Am. Chem. Soc. 2010, 132, 13146-13149. (d) Nun, P.; Gaillard, S.; Poater, A.; Cavallo, L.; Nolan, S. P. Org. Biomol. Chem. 2011, 9, 101104. (e) Poater, A.; Ragone, F.; Correa, A.; Szadkowska, A.; Barbasiewicz, M.; Grela, K.; Cavallo, L. Chem.-Eur. J. 2011, 16, 14354-14364. (f) Mariz, R.; Poater, A.; Gatti, M.; Drinkel, E.; Burgi, J. J.; Luan, X. J.; Blumentritt, S.; Linden, A.; Cavallo, L.; Dorta, R. Chem.-Eur. J. 2010, 16, 14335-14347. (g) Poater, A.; Ragone, F.; Mariz, R; Dorta, R.; Cavallo, L. Chem.-Eur. J. 2010, 16, 1434814353.

(34) (a) Tomasi, J.; Persico, M. Chem. Rev. 1994, 94, 2027-2094. (b) Barone, V.; Cossi, M. J. Phys. Chem. A 1998, 102, 1995-2001. 